\title{
SCHOOL STAFF'S PERCEPTIONS AND ATTITUDES TOWARDS
}

CYBERBULLYING

BY

LORETO MATTIONI

\author{
A thesis \\ Submitted to the Victoria University of Wellington \\ In fulfilment of the requirements for the degree of \\ Master of Education
}

Victoria University of Wellington

(2013) 



\begin{abstract}
Parallel with the spread of technology use, cyberbullying has become a serious problem in schools, particularly those in developed countries where most young people have ready access to the Internet and mobile phones. Cyberbullying can cause significant emotional harm, disrupt social development, and can be associated with negative student outcomes. As schools must provide students with a safe learning environment, they are challenged with ways to address the phenomenon of cyberbullying. To minimize the negative effects of cyberbullying, and to assist school staff to understand and address this issue, it is necessary to examine the views of school staff on cyberbullying. Positioned within the framework of Social-Ecological Theory, this study explored teachers' and senior managers' perceptions and attitudes towards cyberbullying. Data were collected using an anonymous online self-report questionnaire on cyberbullying. One hundred and twelve senior managers and ninety eight teachers, currently working in New Zealand schools, participated in the study. An exploratory factor analysis was conducted to evaluate whether groups of items of the questionnaire assessed distinct attitudinal constructs. Results from the exploratory factor analysis indicated that attitudes towards cyberbullying was a multi-dimensional construct composed by three factors (i.e., 'Concern', 'Empathy' and 'Responsibility'). The results also showed that most school staff understood what behaviours constitute cyberbullying. However, a significant proportion of school staff were unlikely to identify social exclusion as being a component of cyberbullying. School staff perceived cyberbullying as conducted mainly by girls and by students across all age groups. In addition, school staff were concerned about cyberbullying, they were empathetic towards cybervictims and they believed that cyberbullies could be helped. However, school staff, especially senior managers, were unlikely to perceive cyberbullying as a problem in their schools and likely to report low frequencies of cyberbullying. Moreover, school staff felt only moderately responsible for preventing cyberbullying as it commonly occurs outside the school. Theoretical and applied implications, for the different levels of the Social-Ecological Theory that affect cyberbullying behaviours, are discussed.
\end{abstract}




\section{Acknowledgements}

This thesis would not have been possible without the support of many people. I wish to express my gratitude to my supervisor, Associate Professor Vanessa Green who offered invaluable assistance, support, guidance, and excellent supervision during all the stages of my thesis. Deepest gratitude is also due to Dr. Flaviu Hodis and Dr. Dalice Sim for their assistance with statistics and Mabel Harmon for her proofreading.

I would also like to convey thanks to the participants, teachers and senior managers, for their time and contribution to this thesis.

Special thanks to my friends and colleagues who were working on their research at the same time as I was. I appreciate the discussions and conversations about our research and issues that came up. I will treasure those moments for a long time.

I wish to express my love and gratitude to my partner, Julio, for his encouragement, understanding, patience, and love, through the duration of my studies. Special thanks also to my parents, Rodrigo and Cecilia, my siblings, Carolina and Gonzalo, my grandma Porota, and my aunty Ina, for their support, and endless love during my stay in New Zealand. I love you all. 


\section{Table of Contents}

Abstract $\quad$ i

Acknowledgements $\quad$ ii

Listing of Tables $\quad$ vi

CHAPTER ONE: Introduction and literature review 1

1.1. Introduction 1

1.2. Literature review 2

1.2.1. Definitions 2

1.2.2. Cybervictims and perpetrators 7

1.2.3. Gender and age differences in cyberbullying implication 8

$\begin{array}{ll}\text { 1.2.4. Social-ecological framework } & 10\end{array}$

1.2.5. Teachers' perceptions and attitudes towards bullying and cyberbullying $\quad 11$

1.2.6. Contextual and individual factors affecting teachers' attitudes 13

1.2.7. Senior managers' perceptions and attitudes towards cyberbullying 18

1.2.8. Summary 19

1.2.9. Aim and Research Questions 19

CHAPTER TWO: Method 21

2.1 Method of data collection 21

2.2. Participants and Setting 21

2.3. Measures 23

2.4. Procedure $\quad 24$

CHAPTER THREE: Results 26

3.1. Introduction 26

3.2. Research Plan 26

3.3. School staff's perceptions about cyberbullying 26

3.3.1. Definition of cyberbullying 26

3.3.2. Awareness of cyberbullying 27

3.3.3. Gender and age of students implicated in cyberbullying 29

3.4. School staff's attitudes towards cyberbullying 31

3.4.1. Responsibility to address cyberbullying 38

3.4.2. Empathy for cybervictims 38

3.4.3. Concern about cyberbullying 38

3.4.4. Attitudes towards cyberbullies $\quad 39$ 
3.5. Summary of findings

3.6. Qualitative findings $\quad 40$

3.6.1. Parents/Community involvement 40

3.6.2. Students' support $\quad 41$

3.6.3. Bullying/Cyberbullying location 41

3.6.4. Problems with definitions 42

CHAPER FOUR: Discussion $\quad 43$

4.1. Introduction $\quad 43$

4.2. Perceptions of cyberbullying 44

4.2.1. Awareness of cyberbullying occurrence $\quad 44$

4.2.2. Definition of cyberbullying 46

4.2.3 Gender and age of students implicated in cyberbullying 47

4.3. Attitudes towards cyberbullying 48

4.3.1. Concern 48

4.3.2. Empathy 49

4.3.3. Responsibility $\quad 50$

4.4. Summary $\quad 51$

4.5. Methodological contributions to the field 51

4.6. Limitations and further research 52

4.7. Theoretical and applied implications 53

4.7.1. Individual level $\quad 54$

4.7.2. Family level $\quad 54$

4.7.3. Peer group level 55

4.7.4. School level 56

4.7.5. Community level $\quad 57$

4.7.6. Culture level 58

4.7.7. Internet/online level $\quad 58$

4.8. Summary $\quad 59$

$\begin{array}{ll}4.9 \text { Conclusion } & 60\end{array}$

$\begin{array}{lll}\text { 5. References } & 61\end{array}$

Appendices $\quad 66$

Appendix A: Information sheet 66

Appendix B: Online Survey 'Bullying in Schools' 
Appendix C: Additional tables 


\section{Listing of Tables}

Table 1. Behaviours that constitute cyberbullying (Kowalski et al., 2008).

Table 2. Participants' position within the school as a function of gender and level of experience in schools.

Table 3. Amount of cyberbullying observed by position within the school.

Table 4. Perceptions about the gender of students implicated in cyberbullying by position within the school.

Table 5. Perceptions about the age of students implicated in cyberbullying by position 31 within the school.

Table 6. Factor loadings based on Principal Axis Factoring with varimax rotation for 35 11 items for teachers.

Table 7. Factor loadings based on Principal Axis Factoring with varimax rotation for 36 11 items for senior managers.

Table 8. Descriptive statistics for the three scale factors for teachers $(\mathrm{N}=86)$.

Table 9. Descriptive statistics for the three scale factors for senior managers $(\mathrm{N}=97)$. 38

\section{Listing of Figures}

Figure 1. School staff's frequency histogram of 'Cyberbullying is a problem among students at our school'

Figure 2. Teachers' frequency histogram of Factor 1 (Responsibility)

Figure 3. Teachers' frequency histogram of Factor 2 (Empathy)

Figure 4. Teachers' frequency histogram of Factor 3 (Concern)

Figure 5. Senior managers' frequency histogram of Factor 1 (Responsibility)

Figure 6. Senior managers' frequency histogram of Factor 2 (Empathy)

Figure 7. Senior managers' frequency histogram of Factor 3 (Concern)

Figure 8. School staff's frequency histogram of attitudes towards cyberbullies 


\section{CHAPTER ONE: Introduction and literature review}

\subsection{Introduction}

The United Nations Convention on the Rights of the Child recognises a child's right to a safe environment and protection from all forms of harm, including bullying in schools. However, schools are not always a safe and protective place for students. Bullying is recognized as one of the major problems facing schools today (Carroll-Lind, 2009; Olweus, 2004). In addition, the use of new technologies such as the Internet and mobile phones, has introduced the risk of cyberbullying. Recent research found that about one in ten students reported being victims of cyberbullying (Marsh, McGee, Nada-Raja, \& Williams, 2010; Smith, Mahdavi, Carvalho, Fisher, Russell, \& Tippett, 2008). Society's concern about the spread of cyberbullying has increased because it has an extremely negative impact on the social and emotional development of the students involved in cyberbullying (Kowalski, Limber, \& Agatston, 2008; Raskauskas \& Stoltz, 2007). Headlines such as: "Government to crackdown on cyber bullies", and "Schools demand powers to search cyber- bullies" are frequently seen in the media (Hill, 2012, May 13; Vance, 2012, May 11). Moreover, cyberbullying has been linked to reports of suicide in New Zealand (Carroll-Lind, 2009).

Due to the significant societal problems associated with cyberbullying, school staff need to be prepared to prevent and deal with this issue and schools should take actions to intervene in cyberbullying episodes. However, recent studies have found that school staff are not usually clear about how to address cyberbullying (Cross, Shaw, Hearn, Epstein, Monks, and Lester (2009). Moreover, school staff are not sure about their responsibility in addressing this issue because it mostly occurs outside school hours (Mannix \& Moynihan, 2010). School staff can have a potential influence, either positive or negative, on student interactions. Thus, a comprehension of school staff's views on cyberbullying is critical to help them develop a good understanding of this issue and develop skills to manage it. This study explored the social context of cyberbullying through the examination of teachers' and senior managers' perceptions and attitudes towards cyberbullying.

This study is divided into four parts. In Chapter one an introduction of the study and a review of the relevant literature are presented. This review provides an overview of school bullying before focusing on the specific issue of cyberbullying. Then, the review presents an outline of the adaptation of the Social-Ecology Theory for bullying behaviours, previous 
studies on the field of bullying and cyberbullying and the aims and research questions of the current study. This is followed by Chapter two, which focuses on the methods used in the present study. Next, Chapter three presents the results of the study, including an analysis of the demographics variables, and descriptive and inferential statistics for participants' responses. This chapter also presents the results of an exploratory factor analysis of the attitudinal scale used in this study. This analysis yielded three factors that were used to answer research questions related to school staff's attitudes and perceptions. Finally, Chapter four focuses on the discussion of the findings of the study related to senior managers' and teachers' perceptions and attitudes towards cyberbullying. This chapter also presents the limitations of the study, recommendations for further research, the theoretical and applied implications based on the adaptation of the Social-Ecological Theory for bullying behaviours and the conclusion.

\subsection{Literature review}

\subsubsection{Definitions}

Bullying is a form of aggressive behaviour directed at a person or group of people. Smith (1997, p. 1) states that bullying can be described as "the systematic abuse of power persistent and repeated actions which are intended to intimidate or hurt another person". Kowalski, Limber, and Agatston (2008) indicate that sometimes the abuse of power involves differences in physical strength between individuals, but often it is characterized by differences in social power or status. Bullying also includes direct and indirect aggressive behaviour, discrimination and harassment (Smith, 1997).

School bullying is a subcategory of bullying which is present in many classrooms. One definition of school bullying is that "a student is being bullied or victimized when he or she is exposed, repeatedly and over time, to negative actions on the part of one or more other students" (Olweus, 1999, p. 10). Researchers who focus on bullying in schools distinguish several types of bullying. Often they are divided into two categories. The first category refers to traditional or overt. This type of bullying is conducted face-to-face and includes physical and verbal aggression. The second category refers to non- traditional or covert bullying. This type is not easily seen by adults or others and includes: indirect (done via a third party), and relational aggression (conducted to damage someone's peer relationship) (Cross, et al., 2009).

The issue of school bullying occupies a major role in the national consciousness of many countries. International studies that focused on the prevalence of bullying showed that 
students experience high rates of bullying in schools. For example, in the United States, the prevalence estimated of victimization in students aged 6- 10 years was 11\% (Nansel, Overpeck, Pilla, Ruan, Simons-Morton, \& Scheidt, 2001). In the UK, Smith, Mahdavi, Carvalho, Fisher, Russell, and Tippett (2008) found that that 19\% of the pupils aged 11-16 years were bullied during that year.

The United Nations Convention on the Rights of the Child recognises a child's right to a safe environment and protection from all forms of physical and emotional harm, including school bullying (United Nations, 1989). In the New Zealand context, the National Administration Guidelines (NAGs) for school administration set out the following statements of desirable principles:

- "Provide a safe physical and emotional environment for students (NAG5 a); comply in full with any legislation currently in force or that may be developed to ensure the safety of students and employees" (NAG5 c) (Ministry of Education, 2009).

Although schools are expected to provide a safe environment for students and school staff, indications are that school is not always a safe place for students. According to CarrollLind (2009), violence and bullying-related incidents are a major threat to students' wellbeing and contribute to a significant number of school suspensions in New Zealand. Recent studies have revealed high levels of bullying in New Zealand schools compared to other countries. For instance, the Trends in International Mathematics and Science Study (TIMSS 2006/07) found that rates of physical and emotional bullying in New Zealand schools are more than 50 percent above the international average (International Association for the Evaluation of Educational Achievement, 2008). Furthermore, in recent years, new forms of school bullying emerged in New Zealand and other developed countries. These new forms of school bullying are related to new information and communication technologies. Currently, most of the population, including young people, in developed countries use both mobile phones and the Internet. In New Zealand $73 \%$ of youth aged 12 to 19 years old use a mobile phone, and $69 \%$ of those who do not have a phone, report that they use other people's mobile phones (Netsafe, 2005). In addition, the Youth Connected Project-2006 found that $72.4 \%$ of youth aged 10 to 15 years use the Internet (Kleeb, 2007). Thus, about $73 \%$ of the young population in New Zealand use both mobile phones and the Internet.

With the increasing popularity of electronic technology has come the opportunity for "cyberbullying". It is also known as electronic bullying or online social cruelty. It has been 
stated that cyberbullying can have both covert and overt dimensions (Spears, Slee, Owens \& Johnson, 2009). When cyberbullying is done secretly, clandestinely, the bullying can be said to be covert. However, when cyberbullying is open, deliberate acts employing technology for the purpose of harming it can be construed as overt bullying (Spears et al., 2009). Therefore, for students' point of view, cyberbullying seems to involve both covert and overt behaviours. However, for the purpose of this project, cyberbullying is considered a sub-type of covert bullying as it is a behaviour that may be hidden from school staff (Cross et al., 2009). Raskauskas and Stoltz (2007) define cyberbullying as "a means of bullying in which peers use electronics to taunt, threaten, harass, and/or intimidate a peer" (Raskauskas \& Stoltz, 2007, p.565). Smith and Slonje (2010, p.249) define cyberbullying as "an aggressive, intentional act carried out by a group or individual, using electronic forms of contact, repeatedly and over time against a victim who cannot easily defend him or herself".

Some authors have stated that it is necessary to distinguish between the methods by which cyberbullying is carried out and the kind of behaviour transmitted via those methods. There are different methods that can be used to cyberbully others. Smith et al. (2008) identified seven common methods of cyberbullying: mobile phone call bullying, text message bullying, picture bullying, video clip bullying, e-mail bullying; bullying through instant messaging, and bullying via websites. Kowalski et al. (2008) added three more methods that are commonly used to cyberbully others. These methods are: bullying through social networking sites, bash boards, or Internet gaming. As for the behaviours that could constitute cyberbullying, they are outlined by Kowalski et al. (2008) (see Table 1). 
Table 1. Behaviours that constitute cyberbullying (Kowalski et al., 2008).

\begin{tabular}{|c|c|}
\hline Behaviour & Definition \\
\hline Flaming & $\begin{array}{l}\text { A brief, heated exchange between two or more individuals that occurs in } \\
\text { "public" settings, such as chat rooms or discussion groups. }\end{array}$ \\
\hline Harassment & Repetitive offensive messages sent to a target. \\
\hline Denigration & Information about another that is derogatory and untrue. \\
\hline Impersonation & $\begin{array}{l}\text { The perpetrator poses as the victim, most often by using the victim's } \\
\text { password to gain access to his/her accounts, then communicates } \\
\text { inappropriate information with others as if the target himself or herself } \\
\text { were voicing those thoughts. }\end{array}$ \\
\hline $\begin{array}{l}\text { Outing and } \\
\text { trickery }\end{array}$ & $\begin{array}{l}\text { Sharing personal, often embarrassing information with others with whom } \\
\text { the information was never intended to be shared. }\end{array}$ \\
\hline $\begin{array}{l}\text { Exclusion/ } \\
\text { ostracism }\end{array}$ & $\begin{array}{l}\text { Exclusion in the online world can occur in any type of password-protected } \\
\text { environment or by a target being knocked off of buddy list. }\end{array}$ \\
\hline Cyberstalking & $\begin{array}{l}\text { Stalk another person through repetitive harassing and threatening } \\
\text { communications. }\end{array}$ \\
\hline $\begin{array}{l}\text { Happy } \\
\text { slapping }\end{array}$ & $\begin{array}{l}\text { People slap someone, while another individual captures the violence using } \\
\text { a camera phone. The video that is taken of the incident is then downloaded } \\
\text { onto the Web for thousands to see. }\end{array}$ \\
\hline
\end{tabular}

It is important to highlight that there are some similarities as well as differences between traditional bullying and cyberbullying. The literature suggests that involvement in cyberbullying correlates quite highly with involvement in traditional bullying. Some studies have found that students involved in cyberbullying are a subset of those involved in traditional bullying, and they replicate the same behaviours in a different environment. For instance, Ybarra and Mitchell (2004) investigated cyberbullying in 1,501 Internet users aged 10-17 years in the USA. Fifteen percent of the sample were cyberbullies, 51\% of cyberbullies were also traditional victims, and $20 \%$ were cybervictims In addition, in an ethnographic study, Maher (2008) reported that where there was face to face bullying, analogous behaviour was evident in the online environment. However, many traditional victims or bullies are not cybervictims or bullies, since cyberbullying is less frequent than traditional bullying.

Cyberbullying differs from traditional bullying in many ways. Traditional bullying by definition implies repetitive behaviours. But in the case of cyberbullying, the bully may initiate the act and it can be repeated by others without further contribution of the bully 
(Smith \& Stonje, 2010). Thus, the use of recurrence as a criterion for traditional bullying may be less reliable for cyberbullying. There is also a difference between the characteristics of the students implicated in bullying and cyberbullying. According to Strom and Strom (2006), cyberbullies can be physically weaker that the victim, they are mostly anonymous, and they may not know the distress caused by their behaviour. Moreover, cyberbullying can reach a wider audience than traditional bullying (Strom \& Strom, 2006). In addition, cyberbullies are hard to identify. In most cases cyberbullies know their victims, but their victims may not know the cyberbullies. As it is usually very difficult to identify cyberbullies, they do not have to own their actions, so they do not fear being punished for their actions (Belsey, 2006). Also, for the first time, not all school-related bullying occurs in real-time, or in the "real" world of schools (Spears \& Zeederberg, 2012). Raskauskas and Stolt (2007) noted that cyberbullying can go on for the whole day even in cybervictims' homes, something that is not happening with traditional bullying, which usually remains in the school grounds. In addition, adults do not know from first hand, experience, what it means to be a child or an adolescent in this social-median driven context (Spears \& Zeederberg, 2012). These differences between traditional bullying and cyberbullying make cyberbullying a type of bullying with its unique features.

The perpetration of cyberbullying has appeared at different rates in different countries. For instance, in USA, Raskauskas and Stoltz (2007) surveyed 84 adolescents between the ages of 13-18 years on different types of cyberbullying. Almost half (49\%) of the youth reported being cybervictims. The most common form of electronic victimization was text messaging (experienced by 32\%), followed by Internet/website (16\%) (Raskauskas \& Stoltz, 2007). In the UK, Smith et al. (2008) surveyed 533 pupils aged 11-16 years. They found that $19.4 \%$ of the students reported being bullied during the current term, and $10.4 \%$ of them reported being cyberbullied during the same period (Smith, et al., 2008). Similarly, in New Zealand, Marsh et al. (2010) carried out an online survey among 1,169 secondary students. The results showed that nearly half of the participants had been bullied in the current school year, and $11 \%$ of them reported being cyberbullied during the same period of time (Marsh et al., 2010).

Overall, there is a lack of a widely accepted operational definition and measurement of cyberbullying, so results from different studies are difficult to compare. Thus, it is hard to have a consensus of cyberbullying prevalence (Kiriakidis \& Kavoura, 2010). However, two 
conclusions can be drawn. First, cyberbullying exists among the youth population. Second, cyberbullying is less frequent than traditional bullying, but is still significant.

\subsubsection{Cybervictims and perpetrators}

Cyberbullying is unique in terms of the characteristics of the students implicated and the effects of cyberbullying on them. Many researchers examined characteristics associated with cybervictims. Some authors found that most cybervictims are also victims of traditional bullying (e.g., Raskauskas \& Stoltz, 2007; Ybarra, Diener-West, \& Leaf, 2007). Marsh et al. (2010) found that students who experienced text bullying were also significantly more likely to experience other forms of bullying, such as verbal, physical, and relational. Moreover, it was found that cybervictims were also more likely to be cyberbullies. Some authors stated that students more likely to be bullied online were those who were bullying others online (e.g., Smith, et al., 2008; Ybarra, Mitchell, Wolak, \& Finkelhor, 2006).

Li (2006) found that half of the victims of cyberbullying had above average grades, whereas fewer than a third of cyberbullies had above average grades. In addition, it was found that youth who used the Internet for instant messaging, blogging, and chat rooms were more likely to be cyberbullied in comparison to youth not engaging in such behaviours (Ybarra, et al., 2006). Ybarra, Espelage, and Mitchell (2007) found among a sample of 1,588 youth that cybervictims were likely to experience poorer parental monitoring and caregiverchild emotional bonds.

The literature suggests that cyberbullying has a negative impact on the victims. The impact on victims tends to parallel those of traditional bullying. Victims of traditional school bullying often report feelings of depression, low self-esteem, helplessness, social anxiety, reduced concentration, alienation, and suicidal ideation (Kowalski, et al., 2008). Victims of cyberbullying reported similar effects as a result of their victimization. Raskauskas and Stoltz (2007) reported that most victims of electronic bullying felt that the bullying negatively affected them, making them feel sad, hopeless and depressed. Ybarra et al. (2006) noted that cybervictims had borderline/clinically significant problems. In addition, Marsh et al. (2010) stated that cybervictims were significantly more likely to feel unsafe at school compared with students who had not been cyberbullied. Cybervictims were also more likely to miss school (Marsh, et al., 2010), to report having detentions or suspensions, ditching or skipping school, and carrying weapons at school (Ybarra et al., 2007). Furthermore, in New Zealand, some cases of suicides have been linked to cyberbullying (Raskauskas, 2007). 
Researchers have also examined characteristics associated with cyberbullies. Some authors found that cyberbullies had often been traditional bullies (e.g., Smith et al., 2008). Findings regarding the psychosocial characteristics of cyberbullies were reported by Ybarra et al. (2007). Overall, they found that youth who were cyberbullies had poor emotional bonding with parent, and their parents were less likely to monitor their activities in comparison to youth uninvolved in cyberbullying (Ybarra et al., 2007). Some researchers have examined the negative consequences of cyberbullying for perpetrators. Ybarra and Mitchell (2004) reported data from the Second Youth Safety Survey of 1,501 youth aged between 10 and 17 years old regarding the impact of cyberbullying in bullies. Their results suggested that cyberbullies were likely to report a number of psychosocial problems, such as substance abuse, delinquent behaviour and being the target of traditional bullying. These issues were each related to an increase of reported online harassment in the previous year (Ybarra \& Mitchell, 2004). Cross et al. (2009), found that students who covertly bullied others, such as cyberbullies, reported lower levels of connectedness to their schools, felt less safe at school and were more likely to present emotional symptoms, conduct problems and peer relationship problems, compared with students who were not bullies. Moreover, Kowalski, Limber, and Agatston (2008) found that some perpetrators of cyberbullying reported feeling guilt and regret, particularly those who are more tuned in to the negative effects that bullying has on the victim.

In summary, the effects of cyberbullying on both cybervictims and cyberbullies are similar to those produced by traditional bullying. However, some authors stated that cyberbullying can be more damaging than traditional bullying as it can occur out of the school environment and students cannot escape cyberbullying (e.g., Marsh et al., 2010). In addition, students who cyberbully others are relatively protected by the anonymity of electronic forms of contact, so it may lead to more hostile behaviours than traditional bullying (Ybarra \& Mitchell, 2004). Also, in contrast to traditional bullying, the public nature of cyberbullying increases the potential negative impact of the cruelty relative to traditional bullying (Kowalski, et al., 2008). Although it is unclear if the effects of cyberbullying are more damaging than those of traditional bullying, it is clear that cyberbullying from peers can disrupt adolescents' emotional and social development.

\subsubsection{Gender and age differences in cyberbullying implication}

Research on gender differences in aggression implication showed that males engaged in more direct forms of aggression, such as physical bullying, and females engaged in more 
indirect forms of aggression, such as relational bullying (i.e., being socially aggressive towards others) (Crick \& Grotpeter, 1995; Wang, Iannotti, \& Nansel, 2009). In some respects cyberbullying is more like indirect bullying, and one might expect more female involvement. It is not all that surprising, then, that some studies found that cyberbullying occurred more frequently among girls than among boys. For instance, Marsh et al. (2010) found girls were more likely to experience unwanted text messages. Although some studies found that there are no gender differences for being a cybervictim or cyberbully (Smith et al., 2008; Ybarra \& Mitchell, 2004), others have found that males were more likely to be cyberbullies (Li, 2006). Moreover, some researchers have found that boys were far more aggressive than girls when they were implicated in cyberbullying (Maher, 2008). In examining gender differences in cyberbullying reporting, it was found that male cybervictims were less likely to inform adults than female cybervictims ( $\mathrm{Li}, 2006)$.

Despite different findings with regard to gender, there is a consensus about the age of the students involved in cyberbullying. For instance, Raskauskas and Stoltz (2007) found that high school students (approximate ages 15-18) were more likely to be involved in electronic bullying compared to middle school students (approximate ages 12-15). Similarly, Ybarra and Mitchell (2004) and Smith et al. (2008) found that as the age of their sample increased (10 -17 years old), so did the likelihood and frequency of cyberbullying. Cross et al. (2009) investigated school staff's perceptions about the age of students implicated in covert bullying. They found that school staff perceived the prevalence of covert bullying to be highest in the late primary and early high school years (Cross, et al., 2009).Thus, while traditional bullying behaviours tend to show a decline with age (Finkelhor, Ormrod, Turner, \& Hamby, 2005), studies show that the likelihood of being involved with cyberbullying increases with age, possibly because older students have greater access to mobile phones and the Internet.

Little is yet known about school staff's perceptions about the gender and age of students implicated in cyberbullying. In addition, previous findings about the characteristics of students implicated in cyberbullying, from students' point of view, appear doubtful. The area of gender differences is intriguing. While some studies found more female involvement, other studies found more male participation. Moreover, other studies found no gender differences in students implicated in cyberbullying. The area of age is also intriguing. Little is known about when children start cyberbullying. Most studies found that older students were often more involved in cyberbullying behaviours than younger students. However, most 
studies were conducted in the middle or secondary/high school age ranges, and those studies did not include primary school age ranges. The present study seeks to gain an understanding about the gender and age of students implicated in cyberbullying from school staff's point of view.

\subsubsection{Social-ecological framework}

According to Bronfenbrenner's Social- Ecological Theory (1979), the ecological environment influences human development. This perspective is based on the interaction between the developing person and different environmental systems. Bronfenbrenner (1979, p. 3) described the ecological environment as "a set of nested structures, each inside the next". At the innermost level is the immediate setting containing the developing person. He calls this level the microsystem (e.g., family or school classroom). The next levels are the mesosystem (two microsystems in interaction); the exosystem (external environments which indirectly influence development, e.g., parental workplace); and the macrosystem (the larger socio-cultural context) (Bronfenbrenner, 1979).

In recent years bullying has begun to be viewed from a social-ecological framework. Swear and Espelage (2004) adapted Bronfenbrenner's Social- Ecological Theory to explain the phenomena of bullying as a complicated social exchange among different systems (i.e., individuals, family, peer groups, community and culture). That can be explained by the fact that for the first years of a human's life, parents, caregivers, and teachers shape and influence the social ecology environment in which children and adolescents develop (Espelage \& Swearer, 2010). In addition, in recent years, the Internet/online environment has begun to be considered as part of a subsystem (i.e., techno-subsystem) of the child social ecology where digital technologies also impact on child development (Johnson \& Puplampu, 2008).

According to the Social-Ecological Theory, the school environment can influence either engagement in bullying and/or positive social interactions because students spend the majority of their day in schools. One way in which to evaluate school environment is through an exploration of school climate (Holt \& Keyes, 2004). The school climate is composed of the attitudes, perceptions, routines and behaviours of all school community, and can have either positive or negative effects on bullying (Espelage \& Swearer, 2010). Therefore, all members of the school community (i.e., senior managers, teachers, parents, and students) should be involved in creating a positive school climate and in preventing bullying. However, several authors have claimed that it is the adults in the school environment who set the tone 
of the milieu in the school (Carroll-Lind, 2009; Espelage \& Swearer, 2010; Holt \& Keyes, 2004). For instance, senior managers (i.e., principals and deputy principals) are those who frame policies to prevent bullying. In addition, teachers are the front-line people who are supposed to be protecting students from bullying.

The majority of research into school climate has been conducted with teachers. Many authors believe that teachers play particularly important roles in the process of bullying prevention. Yoon and Barton (2008) stated that teachers interact daily with students through instruction, discipline, classroom management, and other school activities. In these interactions teachers are involved in socializing students toward socially acceptable behaviours, creating social environments in which students learn to regulate their behaviours, and interact with other students (Yoon \& Barton, 2008). Because teachers can have significant influence on student interactions, their attitudes, perceptions and practices are components of the school climate that need to be taken into account to prevent bullying and cyberbullying. This study focused on the school level of the Social-Ecological Theory, by including teachers and senior managers.

\subsubsection{Teachers' perceptions and attitudes towards bullying and cyberbullying}

An attitude is a tendency to act in a particular way due to individuals' experiences, beliefs and perceptions (Allport, 1935). Related to that, perception is the process by which individuals detect and interpret information from the world to produce a meaningful experience of it (Lindsay \& Norman, 1977). In other words, what we act is directly influence by our perceptions. In fact, it has been stated that the attitudes of teachers are likely to influence their perceptions of bullying behaviours and then their responses to bullying incidents (Yoon, 2004). In Yoon's (2004) study, teachers' responses to bullying incidents were specifically considered in terms of their impact on the classroom environment, on the perpetrators, and on the victims. Teachers' responses to bullying incidents were likely to contribute to students' perceptions of classroom environments. Teachers who were sensitive to their students responded judiciously to bullying incidents, thereby protecting students from bullying (Yoon, 2004). Sensitive teachers demonstrate that bullying is unacceptable, contribute to an anti-bullying climate in the classroom and make it more likely that students would protect other students (Doll, Song, Champion, \& Jones, 2011). On the other hand, a teacher who models bullying behaviours, or adopts strategies such as tactical ignoring of bullying, is likely to set the tone of the class and send an inappropriate message that bullying is tolerated and even permitted (Yoon \& Kerber, 2003). 
As for the perpetrators, a lack of appropriate consequences may reinforce students' bullying behaviours. Yoon and Kerber (2003) stated that unless appropriate consequences were consistently and immediately given after each bullying incident, bullying behaviours had a greater chance of recurrence, especially when there was continuing success in exerting control over a victim. With victims, a teacher's passive action with a perpetrator may be perceived by the victim as the teacher being uncaring or unable to protect them (Yoon \& Kerber, 2003). Within this context, the victims may fear retaliation from the perpetrator, so the victims are less likely to report in the future that they are being bullied (Pepler, Craig, Ziegler, \& Charach, 1994). As a result of the lack of appropriate interventions, victims will remain silent and continue to be victimised.

Collectively, this demonstrates the importance of teachers' responses to bullying behaviours. Thus, it is important to identify teachers' perceptions and attitudes that may influence their responses to bullying behaviours in general and to cyberbullying in particular. To date, several studies have attempted to determine teachers' attitudes towards bullying. For instance, Boulton (1997) carried out a study in England 15 years ago to determine teachers' attitudes towards bullying, bullies and victims. A standardised questionnaire was completed by 138 school teachers. Boulton (1997) concluded that teachers at that time held generally negative attitudes towards bullying and bullies, and they were generally sympathetic towards victims. More recently, Holt and Keyes (2004) carried out a study in USA. They explored attitudes towards bullying. Participants were 797 teachers and professional/aides from 18 elementary to high schools. They found that teachers maintained positive attitudes towards their students and were generally willing to intervene in bullying situations (Holt \& Keyes, 2004).

Relatively little is known about teachers' attitudes towards the specific issue of cyberbullying. However, two relatively recent studies have attempted to assess teachers' attitudes towards covert forms of bullying. An Australian study conducted by Cross et al. (2009) surveyed 620 staff members from primary and secondary schools to explore their attitudes towards covert bullying behaviours. In this study, the vast majority of staff held a negative attitude towards covert bullying, positive attitudes towards victims and a need to address covert bullying. However, it was found by Yoon and Kerber (2003) that teachers in their study had more negative attitudes towards overt than covert forms of bullying. Ninety four elementary teachers were surveyed reporting that when addressing incidents of covert 
forms of bullying, they were less empathetic to the victim and were less likely to get involved.

\subsubsection{Contextual and individual factors affecting teachers' attitudes}

Some studies have attempted to identify the factors that affect teachers' attitudes towards bullying. According to Craig, Henderson, and Murphy (2000), teachers' attitudes are affected by contextual and individual factors. The contextual factors refer to characteristics of the bullying interaction, such as type of bullying, teachers' awareness of bullying prevalence among the students, the perceived seriousness of bullying situations (Craig, et al., 2000), and the perceived responsibility of the teacher to address bullying (Boulton, 1997). Boulton (1997) stated that if a teacher did not perceive an incident as bullying, was not fully aware of the prevalence of bullying, did not perceive the bullying incident as serious, or did not feel responsible for addressing bullying, they had a passive attitude towards it and they were less likely to intervene (Boulton, 1997; Yoon \& Kerber, 2003). Some of the individual factors that have influenced teachers' attitudes to bullying were gender, empathy and level of experience (Craig, et al., 2000). The individual factors are interdependent with the contextual ones and together influence teachers' attitudes towards bullying.

One of the characteristics of bullying that affect teachers' attitudes towards it is the type of bullying. Teachers were more likely to identify overt bullying, and were less likely to identify covert bullying. Boulton (1997) found that the majority of teachers believed physical assaults, verbal threats, and forcing students do to something against their will could be defined as bullying. However, $25 \%$ of teachers did not define name calling, spreading rumours, intimidation by staring or taking others' belongings as bullying. Furthermore, many teachers did not view relational aggression as bullying (Boulton, 1997). Similarly, Craig et al. (2000) noted that interactions involving physical aggression were labelled as bullying more often, and considered more worthy of intervention than verbal and relational aggression. According to Craig et al. (2000), if teachers' definitions of bullying did not include covert aggression, it was likely that they did not intervene in these types of interactions.

A recent study carried out in Australia to assess school staff's perceptions of covert bullying included cyberbullying. In this study, Cross et al. (2009) found that although $86 \%$ of the primary and secondary staff surveyed felt that most teachers considered sending nasty messages by phone or the Internet bullying, nearly one quarter were unsure if other inappropriate use of the Internet would be considered bullying, with $11 \%$ not considering it 
bullying. In addition, around $20 \%$ of staff stated they did not know whether most teachers at their school would consider students sending other students' private emails, messages, pictures or videos to others without permission to be a form of bullying (Cross et al., 2009).

A second characteristic of bullying interaction that affects teachers' attitudes towards bullying is teachers' awareness of bullying prevalence. This awareness may be affected by the location of bullying (within and outside the school setting) and the number of victims' reporting bullying incidents to teachers. Regarding location, different studies found that cyberbullying occurs in different settings. For instance, Maher (2008) found that cyberbullying occurred both during home-based informal interactions and during schoolbased formal and informal interactions. However, Smith et al. (2008) found that cyberbullying, unlike traditional bullying, is experienced more out of school than in school. Regarding reporting, studies found that rates of victims reporting bullying to someone else tended to be lower for cyberbullying than traditional bullying. For instance, Smith et al. (2008) investigated if students who had ever been bullied or cyberbullied had told anyone. They found that telling was significantly more likely for victims of traditional bullying (70.2\%) than for victims of cyberbullying (58.6\%). This may be explained by the fact that victims of cyberbullying are often afraid to report to adults about being cyberbullied. Students fear that adults will over-react and take away their mobile phone, computer and/or Internet access, which means not being able to socialize or communicate with their peers (Belsey, 2006).

Some researchers found that students who reported cyberbullying incidents did not report them to teachers. MacLoughlin, Meyricke, and Burgess (2009) surveyed 349 students (12-16 years old) in rural Australian schools about their perceptions of cyberbullying. They found that when students were cyberbullied, it was most common for them to tell their friends (about $45 \%$ ) or their parents (about 30\%). Only about 15\% of those surveyed said that they would tell a teacher (McLoughlin et al., 2009). In addition, it was found that bystanders also chose to stay quiet rather than to report cyberbullying incidents to adults. Many bystanders did not think that adults in schools tried to stop cyberbullying when informed ( $\mathrm{Li}, 2008)$. In addition, Cross et al. (2009) found that more than two out of five students who were bullied covertly felt that things stayed the same or got worse after telling an adult. Because of this belief that adults in schools would not help, many victims and bystanders chose not to report cyberbullying incidents. However, it was found that teachers are more likely to intervene in bullying incidents when students reported the incidents to them. Novick and Isaacs (2010) 
investigated the impact of students' reports of bullying on teacher intervention in 115 middle school teachers. They found that being told by students about bullying incidents was the strongest predictor of teacher involvement (Novick \& Isaacs, 2010).

The fact that cyberbullying can occur outside of school and that there is a low rate of cyberbullying reporting to teachers, are relevant signals that must be taken into account since those factors affect teachers awareness about cyberbullying. Teachers cannot respond to cyberbullying if they do not know about its occurrence. In fact, some authors have found that teachers are more likely to intervene to stop overt bullying as opposed to covert bullying (Cross et al., 2009; Yoon \& Kerber, 2003). In addition, Cross et al. (2009) found that there is even less recognition of, and more uncertainty by teachers about how to respond to bullying involving technology compared with other forms of bullying.

Researchers that focused on teachers' awareness about bullying stated that teachers report lower prevalence rates of bullying than students do. For instance, a British investigation found that staff at a secondary school underestimated the frequency with which overt forms of bullying occurred; whereas $26 \%$ of students noted that they had been bullied, staff believed that only $5 \%$ to $10 \%$ had been bullied (Pervin \& Turner, 1994).

Some studies have attempted to investigate teachers' awareness of the prevalence of covert bullying and cyberbullying. Cross et al. (2009), asked school staff to report the percentages of students who are bullied covertly and who covertly bully others for each year level at their school. The authors concluded that many staff were unsure of how many students were covertly bullied or covertly bullied others. A more recent study was carried out in Ireland by Mannix and Moynihan (2010). They surveyed 274 teachers on their perceptions of cyberbullying prevalence among students. The authors found that respondents perceived themselves to have a high level of awareness of cyberbullying. They also indicated perceptions of relatively high levels of occurrence of cyberbullying (Mannix \& Moynihan, 2010).

A third characteristic of the bullying interaction that affects teachers' attitudes towards it is teachers' perceptions of their responsibility to address bullying. The Australian study conducted by Cross et al. (2009) explored the perceived role of school staff in taking responsibility for preventing covert bullying. In this study, the vast majority of staff saw themselves as having responsibility to prevent covert bullying and assist students who are being covert bullied (Cross et al., 2009). However, it has been stated that teachers' 
perceptions of their responsibility to address bullying depends on the location in which bullying takes place. For instance, Boulton (1997) concluded that teachers believed they were less responsible for preventing bullying outside of school grounds than in the classroom or in the playground. Similarly, in Mannix and Moynihan 2010's study, they examined teachers' motivation to intervene in cyberbullying incidents. These authors found that many teachers in the study, some 13 years later, were still unsure of their role and felt that it was not part of their responsibility as teachers as this type of bullying mostly occurs outside of school hours (Mannix \& Moynihan, 2010). However, it has been argued that for teachers considering the problem, the question of where the bullying takes place (in or out of the school) should not be as important as whether the bully was a school student at the time of the incident or someone from outside of school (McLoughlin et al., 2009).

A fourth characteristic of the bullying interaction that affects teachers' attitudes about it, is teachers' perceptions of the seriousness of bullying. Several authors have claimed that teachers view non-traditional forms of bullying less serious than traditional ones and are less likely to intervene than in the case of traditional forms of bullying (e.g., Bauman \& Del Rio, 2006; Yoon \& Kerber, 2003). Craig, Bell and Leschied (2011) investigated pre-service teachers' perceptions of the seriousness of different forms of bullying. The results of their study suggested that covert forms of bullying including relational, homophobic and cyberbullying were viewed as less serious and problematic than overt violence (Craig et al., 2011).

Two studies aimed to explore pre-service teachers' perceptions and understanding of the specific issue of cyberbullying. Li (2008) conducted a study in Canada, where 154 preservice teachers completed a paper-based questionnaire on cyberbullying. Li (2008) found that although a majority of the pre-service teachers were concerned about it, most of them did not think it was a problem in school. More recently, the same study was replicated in Turkey by Yilmaz (2010), where 163 pre-service teachers completed an online survey on cyberbullying. The results of this study showed that Turkish pre-service teachers, unlike preservice teachers in Canada, recognized cyberbullying as a problem and held a strong belief towards cyberbullying' seriousness in school (Yilmaz, 2010). Thus, while both Canadian and Turkish pre-service teachers are concerned about cyberbullying, only Turkish pre-service teachers perceive cyberbullying as a problem in schools. 
A possible explanation for this contradiction is that Turkish pre-service teachers were provided with information about cyberbullying on the questionnaire to set up a general understanding and a web-based survey was used to gather data, as opposed to the paper-based survey that was used in the Yilmaz study (2010). Therefore, the Turkish pre-service teachers compared to the Canadian pre-service teachers, were likely to have more understanding and experience with technology use and they may already know its possible negative effects.

In addition to the contextual factors there are also a number of individual factors that may affect teachers' attitudes towards bullying. One of the individual factors that may affect teachers' attitudes towards bullying is a teacher's gender. Studies found that gender of the teacher is related to the tendency to respond to school violence. Boulton (1997) reported a small but significant difference in teachers' attitudes towards bullying. Males tended to be more tolerant of student aggression than females, and female teachers expressed more negative attitudes towards bullying (Boulton, 1997). Holtz and Keyes (2004) concluded that males were more tolerant to physical aggression, but males and females are more likely to have similar attitudes when verbal bullying is under consideration. In a more recent study, Craig et al. (2011) explored pre-service teachers' perceptions of school violence. They analyzed males and females separately and concluded that females perceived cyberbullying as more serious than males (Craig, et al., 2011).

A second individual factor that may affect teacher' attitudes towards bullying is empathy. The more empathetic a teacher is towards students, then the more likely they will recognise bullying as a problem, and implement appropriate strategies. Craig et al. (2000) found that teachers who were empathetic towards others were more likely to identify bullying, perceive it as serious and report that they would intervene. However, it was found that most teachers felt less empathy towards victims of covert forms of bullying (Yoon \& Kerber, 2003).

A third individual factor that may affect teachers' attitudes towards bullying is teachers' years of experience as teachers. Boulton (1997) stated that in terms of length of experience the level of sympathy to victims decreases with the teachers' length of service. The length of service influences the degree of empathy, in that the less experienced teachers perceive bullying to be more serious that their more experienced counterparts. For instance, Bauman and Del Rio (2006) found that pre-service teachers have significantly higher scores 
on seriousness of a bullying incident, empathy towards victims, and likelihood of intervention when they were compared with in-service teachers.

\subsubsection{Senior managers' perceptions and attitudes towards cyberbullying}

A less researched group within the school environment is the senior management team composed mainly of principals and deputy principals. Senior managers play an important role in the prevention of cyberbullying. They are responsible for ensuring that all students are provided an opportunity to attend school free from fear and aggression. As responsibility includes ensuring that students are using the Internet and mobile devices in a manner that does not cause harm to others (Beale \& Hall, 2007).

The perceptions and attitudes towards cyberbullying of school staff varies greatly depending on how it is defined, who witnesses it and who is asked to report on cyberbullying. Therefore, senior managers' perceptions and attitudes towards cyberbullying can differ from those of teachers. Some researchers have attempted to elucidate the differential perceptions of bullying in schools between school stakeholders. For instance, in United States a study was carried out by Newgent, Lounsbery, Keller, Baker, Cavell, and Boughfman, (2009) to investigate differential perceptions of bullying in the schools between senior managers, teachers, parents, and students. They found that teachers' ratings of bullying were closer to students' ratings when compared to senior managers' ratings, who did not characterize bullying as a problem in their schools (Newgent et al., 2009). Given the likelihood that teachers are dealing with most instances of school bullying, it make sense that school senior managers would under-estimate, more than teachers, the extent to which bullying behaviour is a problem in their school.

The difference between teachers' and senior managers' views on bullying might be also generalized to the specific issue of cyberbullying. Some researchers have found that teachers do not always feel the support of senior managers in addressing cyberbullying episodes. For instance, McQuade, Colt and Meyer (2009) interviewed two teachers from New York who expressed they had received threats from senior managers when trying to stop cyberbullying and cyberbullying was not taken seriously by senior managers. Despite the importance of senior managers' role in establishing climate and addressing bullying, prior research has not explored the perceptions and attitudes of the senior management group about cyberbullying. 


\subsubsection{Summary}

According to the social-ecological model, school staff's perceptions, attitudes and practices have either positive or negative effects on cyberbullying. As teachers' and senior managers' perceptions and attitudes affect their behaviours, understanding these perceptions and attitudes is a necessary first step in helping school staff develop an understanding of and skills to prevent cyberbullying.

To date, the research in this area is limited. Most of the studies have focused on traditional forms of bullying; however, cyberbullying differs from traditional bullying in terms of the characteristics of the students implicated in bullying behaviours, the effects on students, locations, and reporting rates. Secondly, few studies have explored cyberbullying issues through the lens of in-service school staff. Most studies have focused on pre-service teachers. However, the close link between bullying and cyberbullying suggests that preservice teachers' views on cyberbullying may differ from those of in-service teachers. Third, few, if any, studies have examined school senior managers' views on cyberbullying. However, the connection between bullying and cyberbullying suggests that senior managers' perceptions and attitudes towards cyberbullying may differ from those of teachers. Thus, it is imperative to gain a greater understanding about in-service teachers' and senior managers' views on the specific issue of cyberbullying.

\subsubsection{Aim and Research Questions}

Aim: To explore teachers' and senior managers' perceptions and attitudes towards cyberbullying.

Research questions:

- What behaviours do teachers and senior managers perceive to be cyberbullying?

- To what extent are teachers and senior managers aware of cyberbullying occurrence?

- Does the gender and length of experience of school staff influence their awareness of cyberbullying occurrence?

- To what extent are teachers and senior managers concerned about cyberbullying?

- What are teachers' and senior managers' perceptions about the age and gender of students implicated in cyberbullying?

- What are teachers' and senior managers' attitudes towards cyberbullying, cyberbullies and cybervictims? 
- What are teachers' and senior managers' perceptions about their responsibility to address cyberbullying?

- Are there differential perceptions and attitudes towards cyberbullying between teachers and senior managers?

As mentioned above, few preceding studies exist. Therefore, no directional predictions were made in advance. 


\section{CHAPTER TWO: Method}

\subsection{Method of data collection}

In order to answer the research questions a quantitative survey was conducted. To obtain empirical data, an anonymous online self-report questionnaire on bullying was used as a data collection instrument. This method of data collection allowed for the measurement of attitudes and perceptions because it provided information about participants' ways of thinking (Johnson \& Christensen, 2008). One qualitative question was also included to provide respondents with the opportunity of giving their views in an unstructured manner. That qualitative question was analyzed using a thematic analysis, and themes relating to the research questions were identified and presented.

\subsection{Participants and Setting}

As part of a broad survey about bullying in schools, questions about cyberbullying were addressed to primary and secondary school teachers and senior managers (i.e., principals and deputy principals) employed in schools in New Zealand. A list with all New Zealand primary and secondary schools and their respective email addresses was obtained through the New Zealand Ministry of Education website. Surveys were sent to the principals of 2,392 New Zealand schools requesting they answer and forward them to their senior managers and teachers.

The position of participants within the school, gender, and years of experience in schools were analyzed. From a potential sample size of 5,255 senior managers that work in primary and secondary education (Education Counts, 2011), 2.13\% $(\mathrm{n}=112)$ senior managers of the potential sample completed the survey. In addition, this survey could have been answered by 37,119 teachers if it had been passed to all of them. However, $0.26 \%(n=98)$ teachers of the potential sample completed the survey. Of the participants $59.2 \%$ were female and $40.7 \%$ were male.

There are several possible reasons for the low rate of respondents. One possibility is that due to delays in formulating the survey and gaining ethical clearance, the survey was sent out at an inconvenient time for schools (i.e., November), that is at end of school year just before summer vacation. Another possibility is that due to the holiday break, it was not possible to follow up the initial invitation with a reminder to those who did not respond to the survey. An additional possibility is that as bullying/cyberbullying is a sensitive topic, it is fair to hypothesize that many senior managers did not forward the survey to their teachers. This 
will be discussed in more detail in the discussion section. Despite the low response rate, it is important to highlight the value of this study of being one of the first in attempting to survey in-service teachers as well as senior managers about cyberbullying.

As shown in Table 2, of the 210 participants, 112 (51\%) were senior managers and 98 (45\%) were teachers. In addition, $32 \%$ of the 210 participants were female teachers, following by female senior managers (27\%), male senior managers $(26 \%)$, and male teachers $(15 \%)$. The respondents were also asked to indicate how many years they had worked in schools. The participants' experience level ranged from less than 1 year to greater than 20 years. The level of experience of school staff were grouped into three main categories namely early career $(0-6$ years $)$, middle career $(7-20$ years $)$ and later career $(20+$ years $)$. Of the participants, 35 (17\%) reported being beginning career school staff, 78 (37\%) reported being middle career school staff, and 97 (46\%) reported being later career school staff (see Table 2).

Table 2. Participants' position within the school as a function of gender and level of experience in schools.

Position within the school

\begin{tabular}{lcccccc} 
& & \multicolumn{2}{c}{$\begin{array}{c}\text { Teachers } \\
(\mathrm{n}=98)\end{array}$} & & \multicolumn{3}{c}{$\begin{array}{c}\text { Senior Managers } \\
(\mathrm{n}=112)\end{array}$} \\
\cline { 2 - 6 } & Early & Middle & Later & Early & Middle & Later \\
\hline Male & 7 & 15 & 9 & 5 & 13 & 36 \\
Female & 19 & 30 & 18 & 4 & 20 & 34 \\
\hline Total & 26 & 45 & 27 & 9 & 33 & 70 \\
\hline
\end{tabular}

The distribution of participants by type of school and system of education were also analyzed. The participants for this study were employed in different type of schools (i.e., primary, intermediate, intermediate through secondary school and secondary schools), and included all systems of education (i.e., co-educational, all male and all female schools). Results show that over half of the participants (53\%) worked in primary schools, following by secondary schools (32\%). Only $11 \%$ of the participants worked in an intermediate school, 
which provides a transition from primary schooling to secondary schooling, or in an intermediate through secondary school, which provide education from intermediate schooling to secondary schooling. In addition, most of the participants $(93 \%)$ worked in co-educational institutions. Only 9 respondents (4\%) worked in an 'all female school' and 6 respondents $(3 \%)$ worked in an 'all male' school.

\subsection{Measures}

The online survey used in this study was divided into four sections (see Appendix B). The first section gathered information about the personal characteristics of the respondents (i.e., position within the school, years of experience, gender, type of school, year s/he teaches, sector of the school, and decile of the school). Section two asked questions related to school staff's perceptions of the prevalence of different forms of bullying in their schools (i.e., physical, verbal, social/relational and cyberbullying). Section three gathered information about school staff's perceptions of anti-bullying strategies adopted by their schools. Section four gathered information about school staff's views on cyberbullying. Section four contained 9 questions on a nominal scale of yes, no, and don't know responses related to participants' definition of cyberbullying in particular. This section also contained 2 questions related to participants' perceptions about the age and gender of students implicated in cyberbullying, and one question about participants' perceptions of their need of training to deal with cyberbullying. The last part of section four contained 19 questions on a 5-point Likert scale ranging from 'Strongly Disagree' to 'Strongly Agree' related to school staff's perceptions and attitudes towards cyberbullying. A final qualitative question was also included to provide respondents with the opportunity of adding any additional comments.

The last part of section four was developed based on previous questionnaires. Few measures have been developed to assess issues related to cyberbullying. Most of these instruments have dealt with students' perceptions of cyberbullying. Some examples are the 'YISS Survey of Young Regular Internet Users' (Ybarra \& Mitchell, 2004), the 'Netsafe Survey' (Netsafe, 2005), and the 'Internet Experiences Questionnaire' (Raskauskas \& Stoltz, 2007). Only two measures that assessed issues related to cyberbullying addressed teachers' perceptions of cyberbullying. The first measure is the 'Teachers' Perceptions about Cyberbullying Questionnaire' (Li, 2008). The second measure is the 'Teachers' experiences, perceptions of and skills in addressing cyberbullying survey' (Mannix \& Moynihan, 2010). No measures were identified that dealt specifically with teachers' attitudes towards cyberbullying. However, as cyberbullying is a type of covert bullying, a questionnaire 
previously published developed to assess teachers' attitudes towards covert bullying was adapted to explore cyberbullying. Thus, the questionnaire used in the current study was developed based on two previous, field-tested instruments to ensure its validity. The first instrument was "The Peer Relations Assessment Questionnaire" Form C, originally developed by Rigby (1997), and later adapted by Cross et al. (2009). Both versions of the questionnaires sought to determine teachers' perceptions of the prevalence of bullying at the school, and teachers' attitudes towards bullying, bullies and victims. In addition, information provided by these questionnaires included perceived responsibility to address bullying, and views on specific steps that school should take to address bullying. Rigby (1997) developed 'The Peer Relations Assessment Questionnaire' to investigate traditional bullying. Cross et al. (2009) modified that questionnaire to explore covert bullying. The second instrument used in the current study was the 'Teachers' Perceptions about Cyberbullying Questionnaire' (Li, 2008).

The current study modified the Cross et al. (2009) questionnaire. The items were reworded in order to explore school staff's perceptions and attitudes towards the specific issue of cyberbullying instead of covert forms of bullying. For example, Cross et al. (2009) asked school staff to what extent they agree or disagree with the following item 'Teachers should help students deal with covert bullying'. However, the survey used in the present study provided school staff with the following item 'Teachers should help students deal with cyberbullying'. In addition, three questions of the 'Teachers' Perceptions about Cyberbullying Questionnaire' (Li, 2008) were selected to assess school staff concerns about cyberbullying (i.e., 'Cyberbullying is a problem among students at our school', 'Students are affected by cyberbullying' and 'I am concerned about cyberbullying'). The resulting questionnaire included 19 questions related to school staff's perceptions and attitudes towards cyberbullying.

In order to provide an opportunity for a broad range of school staff to report in an efficient, cost effective and convenient way, an online version of the survey was created. The survey was a standardised research tool, in that all participants received identical questions.

\subsection{Procedure}

On 20 October 2011, the Victoria University Faculty of Education Ethics Committee granted ethics approval for this study (Reference number: SEPP/2011/76:RM18902). A pilot sample of 10 in-service teachers pre-tested the online questionnaire. The whole questionnaire 
needed to be tested for length, time to complete and clarity (Punch, 2003). As a result of this pre-test, questions and response options were added, changed, and deleted as needed.

The survey was open to all senior managers and registered teachers in New Zealand schools. On 15 November, 2011, an introductory email explaining the survey was sent to 2,392 school principals in New Zealand. They were asked to answer and forward the survey to their senior managers and registered school teachers to participate in the survey. This introductory email provided a URL link to the survey website. The survey was distributed and collected via the Internet.

The survey website included a covering letter specifying purpose of the study, information about confidentiality, participation and withdrawal, data storage and deletion. The covering letter also provided participants with details about the Human Ethics Approval, reporting and dissemination, who were conducted the study, and a consent statement (Johnson \& Christensen, 2008; Punch, 2003). Appendix A is a copy of the covering letter and the consent statement. The survey was available to participants for one month. The data collected was downloaded into Statistical Programme for Social Sciences (SPSS), version 18. 


\section{CHAPTER THREE: Results}

\subsection{Introduction}

The study investigated teachers' and senior managers' perceptions and attitudes towards cyberbullying in primary and secondary schools. The data were gathered using an online survey. The current study focused on two sections of the large survey on bullying (i.e., section one and section four).

\subsection{Research Plan}

The method followed here was to first examine the personal characteristics of the participants. The analysis of data began with a brief overview of the demographic variables. Following this overview are the descriptive statistics for participants responses to nominal (categorical) questions of the survey. These responses were analysed at the item level to gather information about the distribution of the variables across the population. Next, Chisquare tests were used in order to determine whether an association (or relationship) existed between 2 variables. Items on the continuous scale were scrutinised for underlying patterns via factor analytic procedures. Once clearly defined and interpretable factors had been identified, responses related to these factors were summed to create factor scores. As one of the aims of this study was to examine if teachers' perceptions and attitudes towards cyberbullying differ from those of senior managers, the responses were analyzed as a function of the participants' position in the school (i.e., teachers vs. senior managers). Therefore, factor scores were used as independent variables to conduct t-tests and Wilcoxon Rank Sum Tests.

Thematic analysis was used to analyse the qualitative question. This research technique is a process for encoding qualitative information to identify any current pattern (Boyatzis, 1998). This encoding required an explicit "code". The code used in this study was a list of themes. Each theme is a cluster of linked categories conveying similar meanings (Boyatzis, 1998). The list of themes was generated inductively from the raw information given by participants.

\subsection{School staff's perceptions about cyberbullying}

\subsubsection{Definition of cyberbullying}

Traditionally, overt forms of bullying have been more widely recognised, with covert bulling and cyberbullying only gaining recognition more recently. To have an understanding of the perceptions teachers and senior managers hold regarding cyberbullying, they were 
surveyed about what behaviours (if they happened repeatedly) they considered to be cyberbullying.

A list of nine cyberbullying behaviours was presented to school staff. The results showed considerable agreement among participants about the behaviours they perceived as constituting cyberbullying. About $85 \%$ of the respondents considered using technology to deliver inappropriate messages, calls, and posts as being cyberbullying. The only type of cyberbullying where there was some disagreement was 'ignoring or leaving others out of events over the Internet'. Although more than half of the school staff surveyed (58\%) considered that behaviour as being cyberbullying, 18\% did not consider it as a component of cyberbullying, and $14 \%$ were unsure if it would be considered as being cyberbullying. The frequency of the participants' responses to these behaviours is presented in Table $\mathrm{C} 1$, Appendix C.

Because of the homogeneous nature of the responses about what behaviours were considered to be cyberbullying, it was possible to conduct a Chi-square test of independence for only one of the nine behaviours listed. This test was conducted for the behaviour 'ignoring or leaving others out of events over the internet' as a function of position within the school. The test indicated no significant difference between teachers and senior managers, $\chi 2$ $(2, N=197)=0.005, p=.998$.

\subsubsection{Awareness of cyberbullying}

To assess teachers' and senior managers' perceptions of the extent of cyberbullying among students, two questions were included in the survey. First, the staff were asked to indicate the extent to which they disagree or agree with the following statement 'Cyberbullying is a problem among students at our school'. A significant proportion of the participants (43\%) did not consider cyberbullying as a problem in their school. On the other hand, 79 participants (38\%) considered cyberbullying as a problem in their school. Only 39 respondents $(19 \%)$ neither agreed nor disagreed with the statement. Thus, most of the participants did not consider cyberbullying as a problem in their schools or were unsure about its occurrence $(M=2.79, S D=1.27)$.

In light of previous studies, it was hypothesised that teachers, females, and early career school staff could be more aware of cyberbullying behaviours than senior managers, males and middle/later career school staff. The distribution of scores was examined with 
regard to skewness and kurtosis. The skewness value (-.117) suggests that there was a negatively skewed distribution, where most values are concentrated on the right of the mean with extreme values to the left (Pallant, 2007). The kurtosis value (-1.295) indicates that the distribution is flatter than a normal distribution with a wider peak (Pallant, 2007). Moreover, the examination of the histogram suggested that the distribution was non-normal (see Figure 1, Appendix D). Therefore, nonparametric analyses (Wilcoxon Rank Sum Test) were conducted to compare the amount of agreement between teachers and senior managers, between females and males, and between early and middle/later career with the statement 'Cyberbullying is a problem among students at our school'.

The results revealed a significant difference between teachers $(M=3.24, S D=1.14)$ and senior managers $(M=2.39, S D=1.24) ; Z=4.65, p=.001$. These results suggest that teachers were more likely to report cyberbullying as a problem in schools than senior managers. However, the results revealed no significant difference between female $(M=2.85$, $S D=1.28)$ and male school staff $(M=2.71, S D=1.27) ; Z=0.76, p=.449$. The results also showed no significant difference between early career school staff $(M=2.67, S D=1.11)$ and middle career school staff $(M=2.92, S D=1.32) ; Z=1.13, p=.255$. Moreover, no significant difference was found between early career school staff $(M=2.67, S D=1.11)$ and later career school staff $(M=2.73, S D=1.28) ; Z=0.33, p=.738$. These results suggest that position within the school does appear to have an effect on the perception of cyberbullying as a problem in the school. By contrast, the gender and years of experience of school staff does not appear to have an effect on the perception of cyberbullying as a problem.

To assess school staff's perceptions of the extent of cyberbullying among students, a second question was included. Participants were asked to think about the past four weeks, then indicate the frequency with which cyberbullying was brought to their attention. Variations in the amount of cyberbullying observed might reflect either variation in the actual amount of cyberbullying that is occurring, or in the percentage of cyberbullying that is witnessed by or reported to school staff. More than half of the participants (55\%) reported that cyberbullying had not been brought to their attention in the last 4 weeks. More than one quarter of the participants $(20 \%)$ reported that cyberbullying had been brought to their attention only once or twice in four weeks. Some of the participants $(11 \%)$ reported that they didn't know how many times cyberbullying had been brought to their attention in four weeks. Only $6 \%$ of the participants reported that cyberbullying had been brought to their attention more than once per week. 
Given that teachers had a greater awareness than senior managers it was hypothesised that teachers may report higher frequencies of cyberbullying reporting than senior managers. A chi-square test of independence was performed to examine the relation between the amount of cyberbullying reported and position within the school. The relation between these variables was significant, $\chi^{2}(4, N=202)=16.54, p=.002$. Senior managers were more likely to state a low frequency of cyberbullying reporting. As shown in Table 3,67\% of the senior managers reported that cyberbullying was brought to their attention "Not once in 4 weeks", while only $40 \%$ of the teachers reported low frequency of cyberbullying. On the other hand, $27 \%$ of the teachers mentioned high frequency of cyberbullying in their school ('more than once per week' and 'once a week'), while only $10 \%$ of senior managers reported high frequency of cyberbullying in their school.

Table 3. Amount of cyberbullying observed by position within the school.

\begin{tabular}{ccc}
\hline \multirow{2}{*}{ Cyberbullying frequency } & \multicolumn{2}{c}{ Position } \\
\cline { 2 - 3 } & $\begin{array}{c}\text { Senior manager } \\
(\mathrm{n}=108)\end{array}$ & $\begin{array}{c}\text { Teacher } \\
(\mathrm{n}=94)\end{array}$ \\
\hline Not once in 4 weeks & 72 & 38 \\
Once or twice in 4 weeks & 18 & 21 \\
Once a week & 8 & 10 \\
More than once per week & 4 & 9 \\
Don't know & 6 & 16 \\
\hline
\end{tabular}

\subsubsection{Gender and age of students implicated in cyberbullying}

To gain an understanding of the perceptions participants hold regarding the gender of the students implicated in cyberbullying, teachers and senior managers were asked if cyberbullying was conducted by mainly boys, equal number of boys and girls or mainly girls. The results showed that most of the participants (65\%) reported they perceived cyberbullying as conducted mainly by girls, while $34 \%$ of the participants said they perceived cyberbullying as conducted by equal numbers of boys and girls. As shown in Table 4, only two respondents (1\%) considered cyberbullying as mainly conducted by boys. These two respondents were senior managers, therefore because of this low number, the category 'mainly boys' was removed in order to perform a chi-square test of independence. The test examined the relation between the perceptions about the gender of students implicated in cyberbullying and position within the school. Results of the chi-square test showed that the percentage of respondents who considered cyberbullying as being conducted by equal number of boys and 
girls, or by mainly girls did not differ by position within the school, $\chi^{2}(1, N=181)=1.86$, $p=.172$.

Table 4. Perceptions about the gender of students implicated in cyberbullying by position within the school.

\begin{tabular}{lcc}
\hline Gender of students implicated in cyberbullying & \multicolumn{2}{c}{ Position } \\
\cline { 2 - 3 } & $\begin{array}{c}\text { Senior } \\
\text { manager } \\
(\mathrm{n}=95)\end{array}$ & $\begin{array}{c}\text { Teacher } \\
(\mathrm{n}=88)\end{array}$ \\
\hline Mainly boys & 2 & 0 \\
Equal number of boys and girls & 28 & 35 \\
Mainly girls & 65 & 53 \\
\hline
\end{tabular}

Teachers and senior managers were also asked whether cyberbullying was conducted by mainly children (9-10 years old), mainly younger adolescents (11-14 years old), mainly older adolescents (15-18 years old), or students across all age groups. Results showed that a significant proportion of the participants (44\%) reported they perceived cyberbullying as being conducted by students across all age groups. In addition, 39\% of the participants perceived cyberbullying as being conducted by mainly younger adolescents, while 17\% reported they perceived cyberbullying as being conducted mainly by older adolescents. Only one participant considered cyberbullying as being conducted by mainly children (i.e., 9-10 years old). This respondent was a senior manager. Due to only one respondent considering cyberbullying as mainly conducted by mainly children, this category was combined with 'mainly younger adolescents' category in order to perform a chi-square test of independence. The test examined the relation between the perceptions about the age of student implicated in cyberbullying and position within the school. Results of the chi-square test of independence show that the percentage of respondents who considered cyberbullying as being conducted by mainly children/ younger adolescents, by mainly older adolescents, or by students across all ages did not differ by position within the school, $\chi^{2}(2, N=180)=1.29, p=.523$. Table 5 details the frequencies of participants' perceptions about the age of students implicated in cyberbullying and position within the school. 
Table 5. Perceptions about the age of students implicated in cyberbullying by position within the school.

\begin{tabular}{lcc}
\hline & \multicolumn{2}{c}{ Position } \\
\cline { 2 - 3 } Age of students implicated in cyberbullying & $\begin{array}{c}\text { Senior } \\
\text { manager } \\
(\mathrm{n}=94)\end{array}$ & $\begin{array}{c}\text { Teacher } \\
(\mathrm{n}=86)\end{array}$ \\
\hline $\begin{array}{l}\text { Mainly children/younger adolescents } \\
\text { (9-14 years old) }\end{array}$ & 39 & 31 \\
Mainly older adolescents (15-18 years old) & 17 & 13 \\
Students across all ages groups & 38 & 42 \\
\hline
\end{tabular}

In summary, the school staff's perceptions data revealed that most school staff understood what behaviours constitute cyberbullying. However, a significant proportion of school staff were unlikely to identify social exclusion as being a component of cyberbullying. In addition, school staff, especially senior managers, were unlikely to perceive cyberbullying as a problem in their schools and likely to report low frequencies of cyberbullying. Moreover, most school staff perceived cyberbullying as conducted mainly by girls and by students across all age groups.

\subsection{School staff's attitudes towards cyberbullying}

The questionnaire used in this study was developed based on two previous and reliable measures. The first instrument was "The Peer Relations Assessment Questionnaire" Form C, originally developed by Rigby (1997), and later adapted by Cross et al., (2009). In addition, three items of the 'Teachers' Perceptions about Cyberbullying Questionnaire' (Li, 2008) were included in the survey. The authors of the surveys adapted in the present study did not report any factor analysis. Moreover, those instruments were originally constructed to examine only teachers' attitudes and perceptions. However, in the current study, the adapted instrument was used to assess teachers' and senior managers' attitudes and perceptions. Given the historical use of the questionnaire, it was important to determine the factor structure of the instrument when used to assess teachers' and senior managers' attitudes. In order to assess this, an exploratory factor analysis (EFA), was conducted as it provides information about the interrelationship among a set of variables (Pallant, 2007).

Initially, the factorability of the 19 items was examined. However, prior to performing EFA, the suitability of data for factor analysis was assessed. Inspection of the correlation matrix revealed the presence of many coefficients of .3 and above. An examination of the Kaiser-Meyer Olkin measure of sampling adequacy suggested that the sample was factorable 
$(\mathrm{KMO}=.800)$. In addition, the Bartlett's test of sphericity was significant $(\chi 2(171)=969.88$, $p=.001$ ), indicating that the factor model was appropriate. Given these overall indicators, EFA was conducted.

A principal axis factor analysis with varimax rotation $($ delta $=0)$ was conducted using the 19 questions about cyberbullying adapted from "The Peer Relations Assessment Questionnaire". Results indicated that the answers to this instrument were undefined. There were four reasons to think that:

1. Even though the EFA yielded the existence of six factors; these factors explained only $46.4 \%$ of the variance.

2. Some of the factors revealed by the analysis had a complex structure and did not have clear interpretation.

3. Attempting to use different extraction/rotation methods resulted in convergence problems.

4. Only one or two items by factor were high loading.

Therefore, the sample was split into two sub-samples (i.e., teachers and senior managers) to run a second EFA in order to evaluate whether groups of questions existed with similar underlying characteristics for each sub-sample. Again, the factorability of the 19 items was examined for each sub-sample. Prior to performing EFA, the suitability of data for factor analysis was assessed. Inspection of the correlation matrix revealed the presence of many coefficients of .3 and above. An examination of the Kaiser-Meyer Olkin measure of sampling adequacy suggested that the sample was factorable for teachers $(\mathrm{KMO}=.751)$ as well for senior managers $(\mathrm{KMO}=.746)$. In addition, the Bartlett's test of sphericity was significant for teachers $(\chi 2(171)=525.78, p=.001)$, as well as for senior managers $(\chi 2(171)=$ $597.79, p=.001)$, indicating that the factor model was appropriate. Given these overall indicators, an EFA of the 19 items, using varimax rotation (delta $=0$ ) was conducted for teachers and senior managers separately. Results showed that teachers responded differently from senior managers. In fact, the factors were fewer and more clearly defined for teachers than for senior managers. Data showed six factors explaining $50.61 \%$ of the variance for teachers and seven factors explaining $52.44 \%$ of the variance for senior managers. Moreover, data from senior managers disclosed two factors that were poorly defined. The first factor had similar core of items for both teachers and senior managers, but it includes some extra and 
different items for each sub-sample. Only the second factor was exactly the same for teachers and senior managers.

The three factor solution, which explained $38.98 \%$ of the variance for teachers and $30.37 \%$ of the variance for senior managers, was preferred because of the 'leveling off' of eigenvalues on the scree plot after three factors, and the insufficient number of primary loadings and difficulty of interpreting the fourth and subsequent factors for both teachers and senior managers samples. During several steps, a total of eight items were eliminated for teachers as well as for senior managers because they did not contribute to a simple factor structure and failed to meet a minimum criteria of having a primary factor loading of .4 or above, and no cross-loading of .3 or above.

Prior to performing a third EFA of the remaining 11 items for teachers and 11 items for senior managers, the suitability of data for factor analysis was assessed. Inspection of the correlation matrix revealed the presence of many coefficients of .3 and above. An examination of the Kaiser-Meyer Olkin measure of sampling adequacy suggested that the sample was factorable for teachers $(\mathrm{KMO}=.729)$ as well for senior managers $(\mathrm{KMO}=.782)$. In addition, the Bartlett's test of sphericity was significant for teachers $(\chi 2(55)=285.65$, $p=.001)$, as well as for senior managers $(\chi 2(55)=366.39, p=.001)$, indicating that the factor model was appropriate. Given these overall indicators, an EFA of the 11 items, using varimax rotation $($ delta $=0)$, was conducted for teachers and senior managers separately. As a result of this EFA, it was possible to identify more clearly defined factors to retain in the solution. Results indicated that there are three factors per sample explaining $48.20 \%$ and $49.00 \%$ of the variance after rotation for teachers and senior managers respectively. All the items had eigenvalues greater than 1 . Further, all items had primary loadings over .5. For teachers, only two items had a cross-loading above .3 (i.e., 'It is the responsibility of ALL school staff to stop cyberbullying' and 'Cyberbullying toughens students up'), however, these items were retained because they had a strong primary loading of .611 and .565 respectively. In addition, one item (i.e., 'Cyberbullying is a part of school life which should be accepted') was eliminated because it did not contribute to a simple factor structure. For senior managers, two items had a cross-loading above .3 (i.e., 'Teachers should help students deal with cyberbullying within the school' and 'It makes me angry when students are cyberbullied'). The first was retained because it had a strong primary loading of .744 and the second was eliminated because it had a weak primary loading of .404. The factor loading matrix for these final solutions for teachers and senior managers are presented in Table 6 and 7. 
For teachers, 3 factors had eigenvalues exceeding 1 and accounted for about $48.20 \%$ after rotation.

1.- Factor 1 (eigenvalue $=3.66$ ), which accounted for $29.34 \%$ of the variance and was composed of 4 items assessing issues related to teachers' responsibility and teachers' actions to prevent cyberbullying.

2.- Factor 2 (eigenvalue $=1.83$ ), which accounted for $11.83 \%$ of the variance and was composed of 3 items evaluating attitudes towards cybervictims.

3.- Factor 3 (eigenvalue $=1.14$ ), which accounted for $7.02 \%$ of the variance and was composed of 2 items evaluating concerns about cyberbullying.

For senior managers, 3 factors had eigenvalues exceeding 1 and accounted for about $50.90 \%$ after rotation.

1.- Factor 1 (eigenvalue $=2.38$ ), which accounted for $21.67 \%$ of the variance and consisted of 5 items assessing issues related to senior managers' responsibility and senior managers' actions to prevent cyberbullying.

2.- Factor 2 (eigenvalue $=1.61$ ), which accounted for $14.63 \%$ of the variance and was composed of 3 items evaluating attitudes towards cybervictims.

3.- Factor 3 (eigenvalue $=1.39$ ), which accounted for $12.69 \%$ of the variance and was composed of 2 items evaluating concern about cyberbullying.

The EFA revealed that the first factor, labelled "Responsibility", had a similar core for both teachers and senior managers (i.e., 'Teachers should help students deal with cyberbullying outside of the school'; 'Students who cyberbully others should be spoken to by school staff about their behaviour and given the opportunity to change' and 'Teachers should do more to prevent cyberbullying from happening'). An extra item was included for teachers (i.e., 'It is the responsibility of ALL school staff to stop cyberbullying') and two extra items for senior managers ( i.e., 'Teachers should help students deal with cyberbullying within the school' and 'Students who are cyberbullied need help to ensure the cyberbullying stops').

In addition, three items loaded onto a second factor, labelled "Empathy", for teachers and senior managers: 'Cyberbullying toughens students up'; 'Students who are cyberbullied usually deserve what they get' and 'Students who are cyberbullied should learn to cope with 
it on their own'. Furthermore, the two items that loaded onto factor 3, labelled "Concern", for teachers and senior managers were: 'I am concerned about cyberbullying' and 'Students are affected by cyberbullying'.

Table 6. Factor loadings based on Principal Axis Factoring with varimax rotation for 11 items for teachers.

\begin{tabular}{|c|c|c|c|}
\hline \multirow[t]{2}{*}{ Item Descriptor } & \multicolumn{3}{|c|}{ Factor Loadings } \\
\hline & Responsibility & Empathy & Concern \\
\hline $\begin{array}{l}\text { Teachers should help students deal } \\
\text { with cyberbullying outside of the } \\
\text { school }\end{array}$ & .90 & & \\
\hline $\begin{array}{l}\text { Teachers should do more to prevent } \\
\text { cyberbullying from happening }\end{array}$ & .64 & & \\
\hline $\begin{array}{l}\text { It is the responsibility of ALL school } \\
\text { staff to stop cyberbullying }\end{array}$ & .61 & & .34 \\
\hline $\begin{array}{l}\text { Students who cyberbully others } \\
\text { should be spoken to by school staff } \\
\text { about their behaviour and given the } \\
\text { opportunity to change }\end{array}$ & .50 & & \\
\hline $\begin{array}{l}\text { It makes me angry when students are } \\
\text { cyberbullied }\end{array}$ & & & \\
\hline $\begin{array}{l}\text { * Students who are cyberbullied } \\
\text { usually deserve what they get }\end{array}$ & & .72 & \\
\hline $\begin{array}{l}\text { *Students who are cyberbullied } \\
\text { should learn to cope with it on their } \\
\text { own }\end{array}$ & & .59 & \\
\hline $\begin{array}{l}\text { *Cyberbullying is a part of school life } \\
\text { which should be accepted }\end{array}$ & & .59 & \\
\hline *Cyberbullying toughens students up & & .56 & .30 \\
\hline Students are affected by cyberbullying & & & .87 \\
\hline I am concerned about cyberbullying & & & .62 \\
\hline
\end{tabular}

$*=$ Items that were reversed scored. Note: Factor loading $<.3$ are suppressed 
Table 7. Factor loadings based on Principal Axis Factoring with varimax rotation for 11 items for senior managers.

\begin{tabular}{|c|c|c|c|}
\hline \multirow[b]{2}{*}{ Item Descriptor } & \multicolumn{3}{|c|}{ Factor Loadings } \\
\hline & Responsibility & Empathy & Concern \\
\hline $\begin{array}{l}\text { Teachers should help students deal with } \\
\text { cyberbullying within the school }\end{array}$ & .76 & & .33 \\
\hline $\begin{array}{l}\text { Students who cyberbully others should be } \\
\text { spoken to by school staff about their behaviour } \\
\text { and given the opportunity to change }\end{array}$ & .71 & & \\
\hline $\begin{array}{l}\text { Teachers should do more to prevent } \\
\text { cyberbullying from happening }\end{array}$ & .65 & & \\
\hline $\begin{array}{l}\text { Teachers should help students deal with } \\
\text { cyberbullying outside of the school }\end{array}$ & .55 & & \\
\hline $\begin{array}{l}\text { Students who are cyberbullied need help to } \\
\text { ensure the cyberbullying stops }\end{array}$ & .49 & & \\
\hline $\begin{array}{l}\text { It makes me angry when students are } \\
\text { cyberbullied }\end{array}$ & .40 & & .36 \\
\hline *Cyberbullying toughens students up & & .74 & \\
\hline $\begin{array}{l}\text { *Students who are cyberbullied usually } \\
\text { deserve what they get }\end{array}$ & & .73 & \\
\hline $\begin{array}{l}\text { *Students who are cyberbullied should learn to } \\
\text { cope with it on their own }\end{array}$ & & .54 & \\
\hline I am concerned about cyberbullying & & & .75 \\
\hline Students are affected by cyberbullying & & & .67 \\
\hline
\end{tabular}

$*=$ Items that were reversed scored. Note: Factor loading $<.3$ are suppressed 
A composite score was created for each of the three factors for each sub-sample, based on the mean of the items which were selected. These total scores were used as dependent variables in subsequent tests. Responses were coded so that a high score indicated i) high responsibility to prevent cyberbullying, ii) high empathy for cybervictims, and iii) high concern about cyberbullying.

Descriptive statistics are presented in Table 8 for teachers and Table 9 for senior managers. Internal consistency for each of the scales and for each of the sub-samples was examined using Cronbach's alpha. The alphas were considered acceptable (Pallant, 2007). The distribution of scores was examined with skewness and kurtosis. It is possible to conclude that the skewness and kurtosis were well within a tolerable range for assuming a normal distribution for factor 1 (i.e., 'Responsibility') for both teachers and senior managers. However, skewness values suggest that factors 2 and 3 (i.e., 'Empathy' and 'Concern') had a negatively skewed distribution. In addition, kurtosis values indicate that Factor 2 and 3 had peaked distribution. Furthermore, the examination of the histograms suggested that the distributions looked approximately normal for Factor 1, but non-normal for Factor 2 and 3 (see Figure 2-7, Appendix D).

Table 8. Descriptive statistics for the three scale factors for teachers $(\mathrm{N}=\mathbf{8 6})$.

\begin{tabular}{lccccc}
\hline & No. Of items & M (SD) & Skewness & Kurtosis & Alpha \\
\hline Responsibility & 5 & $3.80(.56)$ & -.47 & 1.03 & .78 \\
Empathy & 3 & $4.52(.58)$ & -1.8 & 5.08 & .74 \\
Concern & 2 & $4.30(.64)$ & -.89 & 1.04 & .73 \\
\hline
\end{tabular}


Table 9. Descriptive statistics for the three scale factors for senior managers $(\mathbf{N}=\mathbf{9 7})$.

\begin{tabular}{lccccc}
\hline & No. Of items & M (SD) & Skewness & Kurtosis & Alpha \\
\hline Responsibility & 5 & $3.97(.56)$ & -.59 & 2.03 & .79 \\
Empathy & 3 & $4.57(.48)$ & -1.07 & .29 & .72 \\
Concern & 2 & $4.36(.62)$ & -.87 & .74 & .67 \\
\hline
\end{tabular}

\subsubsection{Responsibility to address cyberbullying}

As shown in Tables 8 and 9, the mean for teachers and senior managers were quite similar for 'Responsibility'. As the items that composed factor 1 are different for teachers and senior managers, it was not possible to compare the means statistically. However, it is noticeable that the means of 'Responsibility' for teachers and senior managers were lower than the means for 'Empathy' and 'Concern'. Thus, the results suggest that school staff felt moderate responsibility for addressing cyberbullying.

\subsubsection{Empathy for cybervictims}

Tables 8 and 9 show that the means for 'Empathy' were quite high for teachers as well as senior managers. A nonparametric analysis (i.e., Wilcoxon Rank Sum Test) was conducted to compare empathy for cybervictims between teachers and senior managers. The results suggest that there was not a significant difference in the scores for teachers $(M=4.53$, $S D=.581)$ and for senior managers $(M=4.58, S D=.482) ; Z=.34, p=.737$. Thus, the position of staff within the school really does not have an effect on the empathy for cybervictims. Specifically, these results suggest that both teachers and senior managers were empathetic towards cybervicims.

\subsubsection{Concern about cyberbullying}

As shown in table 8 and 9, the means for 'Concern' were quite high for both teachers and senior managers. A nonparametric analysis (i.e., Wilcoxon Rank Sum Test) was conducted to compare concerns about cyberbullying between teachers and senior managers. The results suggest that there was not a significant difference in the scores for teachers $(M=$ 4.30, $S D=.640)$ and for senior managers $(M=4.36, S D=.628) ; Z=.57, p=.567$. Thus, the position within the school really does not have an effect on the concern about cyberbullying. Specifically, these results suggested that both teachers and senior managers were concerned about cyberbullying. 


\subsubsection{Attitudes towards cyberbullies}

To assess teachers and senior managers' attitudes towards cyberbullies, two questions that were not yielded by the EFA were analyzed. The staff were asked to indicate the extent to which they disagreed or agreed with the following statements; 'Students who cyberbully are unlikely to change their behaviour', and 'Punishment is the best way to respond to a student who is cyberbullying others'. Frequencies of the responses were analyzed to determine if school staff answered with a similar pattern to the two items related to cyberbullies (see Table C2 and C3, Appendix C). Results showed that even though more than half of the participants (62\%) disagreed or strongly disagreed with the first statement, more than one quarter of the respondents $(27 \%)$ neither agreed nor disagreed with it. Only $11 \%$ of the respondents agreed or strongly agreed with the first statement. In addition, most of the respondents $(57 \%)$ disagreed or strongly disagreed with the second statement, while $32 \%$ of the respondents neither agreed nor disagreed with it. As in the first item, $11 \%$ of the participants agreed or strongly agreed with the second statement.

The results show that school staff answered with a similar pattern to the two items related to cyberbullies. Thus, a composite score was created for those items. The items were previously reverse scored, so that a high score indicated a strong belief that cyberbullies can be helped. The distribution of scores was examined with skewness and kurtosis. Skewnes value (-.631) and kurtosis value (.997) were well within a tolerable range for assuming a normal distribution (Pallant, 2007). In addition, the examination of the histogram suggested that the distribution looked approximately normal (see Figure 8, Appendix D). Therefore, the total score was used as dependent variable in an independent-samples t-test to compare the attitudes towards cyberbullies between teachers and senior managers. The results suggest that there was not a significant difference in the scores for teachers $(M=3.50, S D=.801)$ and for senior managers $(M=3.66, S D=.687) ; t(189)=1.55, p=.123$. Thus, the position of staff within the school really did not have an effect on the attitudes towards cyberbullies. Specifically, these results suggest that most of teachers and senior managers held a belief that cyberbullies can be helped. However, the means for attitudes towards cyberbullies are slightly lower than those means for empathy for cybervictims.

\subsection{Summary of findings}

The major quantitative findings of this study about teachers' and senior managers' perceptions and attitudes towards cyberbullying can be summarized as follow. First, school staff had a clear idea about what behaviours constitute cyberbullying. School staff were likely to consider inappropriate calls, messages or posts using technology as being cyberbullying. 
The only type of cyberbullying where there was some disagreement was related to online social exclusion. Second, school staff perceived cyberbullying as conducted mainly by girls and by students across all age groups. Third, school staff perceived themselves as moderately responsible for addressing cyberbullying. Fourth, school staff were empathetic towards cybervictims, held a belief that cyberbullies can be helped, and they were concerned about cyberbullying. Finally, although most teachers and senior managers were consistent in how they understood or viewed cyberbullying, there were some discrepancies between them with regard to awareness. Teachers were more likely to perceive cyberbullying as a problem in their schools and to report high frequencies of cyberbullying in their schools than senior managers. However, school staff's perceptions about the prevalence of cyberbullying in their school did not differ according to gender and length of experience.

\subsection{Qualitative findings}

At the end of the survey, participants were asked to share any further comments. Observations about bullying were presented by 40 respondents. These comments were analyzed using thematic analysis in order to identify, analyse and report patterns (themes) (Boyatzis, 1998). There weren't any a priori themes noted as the question was broad and it was simply a way for respondents to add to survey. The thematic analysis of the qualitative data revealed four common themes: parents/community involvement, students' support, bullying/cyberbullying' location, and problems with definitions. These qualitative findings supported and facilitated the interpretation of the quantitative findings.

\subsubsection{Parents/Community involvement}

The most common theme offered by respondents was the importance of parents and community involvement to prevent cyberbullying. Twenty four percent $(24.5 \%)$ of the participants $(\mathrm{n}=17)$ provided comments related to this theme, which consisted of the assertion that cyberbullying is a community issue that needs to be dealt with by everybody involved, schools, students, parents and community. Most of the participants highlighted the importance of parental contribution. For example, one participant reported; "Parents need to take a far greater responsibility for their own children in regards to cyberbullying rather than making the school the default parent for behaviours at any location/time of day". In addition, some participants reported the importance of community participation. For instance, one participant expressed: "parent education from outside agencies is not used enough... outside providers should be working in schools on this problem". Consistent with these qualitative findings, the results of this study indicated that school staff perceived themselves 
as moderately responsible for addressing cyberbullying and stated that parents and community need to take more responsibility.

\subsubsection{Students' support}

The next theme, students' support, was offered by $22.5 \%$ of the respondents $(n=9)$. This theme dealt with the importance of supporting students (i.e., cybervictims and cyberbullies) to stop cyberbullying. Many participants indicated that is important to support students who are being bullied in general or cyberbullied in particular. For example, one participant said: "those being bullied need to know that the environment they are in is supportive and that they will be supported". In addition, some of the participants reported that perpetrators also need to be helped in order to stop the bullying/cyberbullying behaviour. For instance, one participant reported: "a culture of support for bullies and victims needs to be created". Another participant indicated: "the plan must be designed in a manner to help and support both the victim and the offender". Similarly, the quantitative results of this study indicated that school staff felt empathetic towards cybervictims, they held a belief that cyberbullies can be helped, and they were concerned about cyberbullying.

\subsubsection{Bullying/Cyberbullying location}

Another theme offered by respondents was bullying/cyberbullying location. Twenty two percent $(22.5 \%)$ of the respondents $(n=9)$ provided comments related to this theme, which related to the extent school staff view themselves as having responsibility for bullying or cyberbullying that occurs within and outside school. Most of the respondents said that cyberbullying takes place outside of school and therefore it was not their responsibility to address this issue. For instance, one respondent stated " $a$ lot of cyberbullying happens outside school time and parents are unaware of what their children are doing... teachers cannot solve the worlds bullying problems".

By contrast, some respondents reported they perceived themselves as having responsibility for bullying/cyberbullying despite where it takes place. For example, one participant indicated "...we have had only a small number of [cyberbullying] incidents. Although in a sense they were outside the school -mainly on Facebook- they impacted on relationship between students at school. We therefore acted very quickly...” Consistent with these findings, the quantitative results of this study indicated that school staff perceived themselves as moderately responsible for addressing cyberbullying. 


\subsubsection{Problems with definitions}

The fourth theme, which was problems with definitions, was offered by $15 \%$ of the respondents $(n=6)$. This theme referred to the difficulty by school staff, students and parents to distinguish between what is an inappropriate behaviour and what is bullying and/or cyberbullying. One participant expressed: "The word "bullying" has tended to be an overused generic term for all behaviours. Many parents are too quick to use the term instead of rationally finding out what is happening before accusing”. In addition, another respondent stated "the term "bullying" versus multiple incidents involving the same two parties is what I find hard to figure out". The results of this study and these qualitative findings suggest that even though school staff had a clear idea about what behaviours constitute cyberbullying, in practice it was difficult to determine when those behaviours represented harassment/teasing and when those behaviours constituted cyberbullying. 


\section{CHAPER FOUR: Discussion}

\subsection{Introduction}

According to the social-ecological theory, school staff' views and practices may have either positive or negative effects on cyberbullying. As school staff's perceptions and attitudes affect their behaviours, this study aimed to examine teachers and senior managers' perceptions and attitudes towards cyberbullying. The perceptions and attitudes were gauged by considering school staff's responses to an anonymous online survey.

The results of this study were similar to previous literature (e.g., Boulton (1997), Craig et al. (2000), and Cross et al. (2009), in that although school staff were concerned about cyberbullying, they were not fully aware of its occurrence and they were unlikely to identify social exclusion as being a component of cyberbullying. In addition, as in previous studies (e.g., Li (2008), and Mannix \& Moynihan (2010), school staff held positive attitudes towards cybervictims, they believed that cyberbullies can be helped, and they felt moderately responsible for preventing cyberbullying.

However, other results of the current study were contrary to those found in previous studies. For example, results of the present study suggest that gender and years of experience of school staff does not appear to have an effect on the perception of cyberbullying as a problem in schools. However, some previous studies (i.e., Boulton (1997), Holtz \& Keyes (2004), Bauman \& Del Rio (2006), and Craig et al. (2011) found that females and early career school staff were likely to perceive bullying behaviours more seriously than males and middle/later career school staff. In addition, the present study found that school staff perceived cyberbullying as being conducted by students across all age groups. However, previous research that investigated the characteristics of students implicated in cyberbullying from the students' point of view found that older students were more often implicated in cyberbullying than younger students (e.g., Ybarra \& Mitchell (2004), Raskauskas \& Stoltz (2007), and Smith et al. (2008). This is possibly due to the fact that the current study is one of the first that has attempted to elucidate school staff's perceptions of the gender and age of students implicated in cyberbullying including primary school age ranges.

Based on the literature, it was predicted that perceptions and attitudes towards cyberbullying would vary greatly depending how it was defined, who witnessed it, and who was asked to report on cyberbullying. Thus, the survey's answers were also considered in the context of the participants' position within the school (i.e., teachers and senior managers). 
Although most teachers and senior managers were consistent in how they understood or viewed cyberbullying, there were some discrepancies between them in regard to awareness.

The following discussion is divided into five parts. The first part begins by presenting school staff's perceptions of cyberbullying, including their awareness of cyberbullying occurrence, their definition of cyberbullying, and their perceptions of the gender and age of students implicated in cyberbullying. The second part of the discussion presents school staff's attitudes towards cyberbullying, including their concerns about it, their attitudes towards cybervictims and cyberbullies, and their responsibility to address this issue. This is followed by the methodological contributions of the study. Next, the limitations of the present study and recommendations for future research are presented. Finally, the fifth part of the discussion introduces the theoretical and applied implications of the current study for the different levels of the Social-Ecological Theory that affect cyberbullying behaviours and the conclusion.

\subsection{Perceptions of cyberbullying}

\subsubsection{Awareness of cyberbullying occurrence}

The findings suggest that the majority of school staff in the present study did not think cyberbullying was a problem in their schools and they reported low frequencies of cyberbullying among the students in their schools. About three quarter of the participants reported cyberbullying had not been brought to their attention in the last four weeks or it had been brought to their attention only once or twice in four weeks. The low prevalence of cyberbullying reported by school staff might reflect the low percentage of cyberbullying that is witnessed by or reported to school staff. These findings were similar to those found in previous literature. For instance, in the 2009 study by Cross et al., when school staff were asked to state how often they observed or were informed about certain types of bullying, cyberbullying behaviours were reported only by a small percentage of school staff $(12 \%$ or less) (Cross, et al., 2009). Moreover, a Canadian study conducted by Li (2008) found that the majority of pre-service teachers who participated in her study did not think cyberbullying was a problem in the school system.

The findings of the current study were in contrast with some of the literature conducted with teachers. For instance, a study on teachers' perceptions of cyberbullying prevalence among students conducted by Mannix and Moynihan (2010) found that most of the teachers in their study indicated perceptions of relatively high levels of occurrence of 
cyberbullying. However, it is important to highlight that, in Mannix and Moynhan's study, teachers were not asked to provide their perceptions of cyberbullying frequency within limited time constraints, and therefore they may have been thinking over the whole year instead of a more limited time. Those measurement differences between the current study and Mannix and Moynhan's study may explain the difference between the findings.

Moreover, findings of the current study were also in contrast with some of the literature focused on pre-service teachers. For example, Turkish pre-service teachers recognized cyberbullying as a problem in school system (Yilmaz, 2010). However, as noted earlier, Turkish pre-service teachers were provided with detailed information about cyberbullying on the questionnaire, which may have provided them with a better understanding about cyberbullying (Yilmaz, 2010). In addition, pre-service teachers' awareness of cyberbullying prevalence in schools may depend on the experience that they have in school culture. Due to the lack of pre-service teachers' experience in the school culture, it has been found that pre-service teachers' perceptions on all types of bullying differ from those of in-service teachers' (Bauman \& Del Rio, 2006).

Even though school staff who participated in the current study reported low frequency of cyberbullying among their students, the position within the school (i.e., teachers vs. senior managers) appeared to have an effect on the perception of cyberbullying as a problem and on the perception of the prevalence of cyberbullying among students. Teachers were more likely to perceive cyberbullying as a problem in their schools and to report high frequencies of cyberbullying in their schools than senior managers. These finding replicate the literature. For example, Newgent et al. (2009) investigated differential perceptions of different types of bullying in the schools between stakeholders. They found that teachers' ratings of bullying were closer to students' ratings than principals' ratings, who generally did not characterize bullying as a problem in their schools (Newgent, et al., 2009). Given the likelihood that it is teachers who are mostly dealing with instances of school bullying, it makes sense that school senior managers would underestimate, even more than teachers, the extent to which bullying behaviour is a problem in their school.

However, senior managers have a central role in leading prevention and intervention efforts. Senior managers must design and implement anti-bullying programmes. Even though the entire school community should prevent cyberbullying, school senior managers are key to providing the community leadership necessary to bring school staff, parents, students, and 
other community members together to address concerns of cyberbullying and Internet safety (Mason, 2008). Furthermore, some researchers have stated that the leadership by senior managers is critical for the success of an anti-bullying programme. For instance, Olweus (2004) stated that in order for anti-bullying work to be successful it is important that the senior managers allocate time and resources to bullying prevention-relate activities (Olweus, 2004). In addition, Kallestad and Olweus (2003) claimed that senior managers influence staff's attitudes and behaviour by putting anti-bullying work on the school's official agenda, by initiating plenary meetings with staff and parents, and by providing clear guidelines about the organization of the supervisory system during break periods, for example. Therefore, senior managers' lack of awareness of bullying in general and cyberbullying in particular might have a negative impact on its prevalence among students.

\subsubsection{Definition of cyberbullying}

The findings of this study indicated that school staff were likely to consider using technology to deliver inappropriate messages, calls and posts as being cyberbullying. However, a significant proportion of school staff did not view ignoring or leaving others out of events over the Internet as being cyberbullying. In particular, the findings of this study confirmed those of the literature in which school staff were less likely to identify online exclusion as a type of cyberbullying compared to other forms of it. Cross et al. (2009) also found that although most of the staff considered sending nasty messages by email, phone or Internet to be bullying, nearly one quarter were unsure whether excluding others over the Internet would be considered bullying. In addition, other studies that have investigated bullying definitions by teachers have found that many teachers did not consider leaving people out of events to be bullying (e.g., Boulton, 1997; Craig, et al., 2000). Not surprisingly, because social exclusion is a subtle form of bullying, it has been found that a significant proportion of teachers view social exclusion by peers less seriously and are less likely to intervene than in the cases of verbal and physical aggression (e.g., Yoon \& Kerber, 2003).

As was mentioned in the literature review, social exclusion and ostracism conducted over the Internet are behaviours that constitute cyberbullying. However, it appears that the lack of recognition of social exclusion as bullying by school staff extends from bullying that occurs in real space to bullying that occurs in the medium of cyberspace. That can result in negative consequences because even if school staff observe episodes of online exclusion or have these episodes reported to them, if these behaviours are not consistent with the school 
staff's definition of cyberbullying, they will not classify them as such and they will be less likely to intervene.

\subsubsection{Gender and age of students implicated in cyberbullying}

The findings of the present study indicated that school staff perceived cyberbullying as conducted mainly by girls and by students across all age groups (i.e., 9-18 years old). The author is not aware of any study to date that has attempted to evaluate school staff's perceptions about the gender and/or age of the students implicated in cyberbullying, so it is difficult to place the findings in an appropriate context, however, several studies have attempted to identify the characteristics of students implicated in cyberbullying from the students' point of view.

For example, with regard to the gender of the students, Marsh et al. (2010), in their study focused on secondary students, found that in New Zealand, girls were more likely to experience unwanted text messages than boys. In contrast, other studies have found that there are no gender differences for being either a cybervictim or a cyberbully (e.g., Smith, et al., 2008; Ybarra \& Mitchell, 2004), and still others have found that males are more likely to be cyberbullies ( $\mathrm{Li}, 2006$ ), and they bully each other online more than girls (Maher, 2008). Given that the Marsh et al. (2010)'s study was conducted in New Zealand and the other studies were conducted in Europe and North America, it is fair to assert that there may be cultural differences in the use of electronic technologies. This tentative conclusion needs further investigation.

When student respondents were asked about the age of students implicated in cyberbullying, findings from international studies showed that the likelihood of being involved with cyberbullying increased with age. For instance, two studies carried out in USA found that high school students (approximate ages 15-18 years old) reported being more likely to be involved in cyberbullying compared to middle school students (approximate ages 12-15 years old) (Raskauskas \& Stoltz, 2007; Ybarra \& Mitchell, 2004). Similarly, in the U.K., Smith et al. (2008) found that older students (14-16 years old) reported higher frequencies on involvement in cyberbullying when compared to younger pupils (11-14 years old). In New Zealand little is known about the age that children start being implicated in cyberbullying episodes because national studies have been only conducted in secondary schools (e.g., Marsh, et al., 2010). However, from related literature it is known that in New Zealand, $73 \%$ of youth aged 12 to 19 years old use a mobile phone (Netsafe, 2005), and 
$72.4 \%$ of youth aged 10 to 15 years use the Internet (Kleeb, 2007). Thus, there are at least two possible reasons to explain why school staff perceived cyberbullying as being conducted by students across all age groups. One possibility is that younger people are using the Internet and mobile phones, therefore, school staff hypothesize that those young children could be involved in cyberbullying episodes. Another possibility is that young children in New Zealand are actually involved in those incidents. This point also requires further research.

In summary, the findings of this study related to school staff's perceptions of the characteristics of students implicated in cyberbullying support some previous research that found that cyberbullying is mainly conducted by girls. However, some findings of the current study are in contrast to results of previous studies that have investigated the characteristics of students implicated in cyberbullying from the students' point of view. It is important to highlight that it appears that the present study is the first to give school staff the option of providing their opinion about the gender and age of students implicated in cyberbullying. In addition, considering that most of the studies focused on high school students, this study appears to be one of the first that considered younger children as possible victims or perpetrators of cyberbullying.

\subsection{Attitudes towards cyberbullying}

Attitudes towards cyberbullying were analyzed based on the results of an Exploratory factor analysis. These results indicated these attitudes were a multi-dimensional construct composed of three factors (i.e., 'Concern', 'Empathy' and 'Responsibility',). As mentioned in Chapter three, two items that were not yielded by the factor analysis were analysed separately in order to assess teachers' and senior managers' attitudes towards cyberbullies.

\subsubsection{Concern}

Despite having an incomplete definition and an apparent lack of awareness of the frequency of cyberbullying, the findings of this study suggest that school staff were, in fact, concerned about cyberbullying in general. Although it appears that there are no studies to date that have attempted to elucidate school staff's concern about cyberbullying, the findings of the present study supported those of studies on pre-service teachers. For instance, Li (2008) found that most Canadian pre-service teachers were concerned about cyberbullying and its negative impact on the school climate. In addition, Yilmaz (2010) concluded that Turkish pre-service teachers were also concerned about cyberbullying and its effects on students. Although the majority of school staff in the present study were concerned about cyberbullying, they did not think it was a problem in their schools. This shows that, although 
teachers and senior managers understand the negative effects of cyberbullying, they are not fully aware of the significance and prevalence of this problem in their own school. One possible explanation is that the covert nature of cyberbullying makes it difficult to be seen by school staff or that they think that cyberbullying occurs outside of school hours and it is not their realm.

\subsubsection{Empathy}

The findings of this study indicated that both teachers and senior managers held positive attitudes towards cybervictims and a belief that cyberbullies can be helped. Even though it appears that there are no studies to date that have attempted to elucidate school staff's attitudes towards students implicated in cyberbullying, there are some studies that have investigated school staff's attitudes towards students implicated in overt and covert bullying. The findings of the present study confirmed those of recent studies related to covert forms of bullying. In Cross et al.'s 2009 study on school staff's attitudes towards covert bullying behaviours, the vast majority of staff held positive attitudes towards victims of covert bullying and they reported a need to address covert bullying including perpetrators.

On the other hand, the findings of the current study do not support some previous findings related to overt forms of bullying. For instance, Boulton (1997) carried out a study to determine teachers' attitudes towards bullying, bullies and victims. He found that teachers were generally empathetic towards victims, and generally held negative attitudes towards bullies (Boulton, 1997). Boulton's study was carried out 15 years ago and school staff's attitudes towards bullying may have changed along with increase attention to the problem (NetSafe, 2012). In fact, during the last decades overt and covert forms of bullying, including cyberbullying, have received wide attention in the media (Carroll-Lind, 2009) and school staff may have been influenced by that information. Thus, given the constantly evolving and changing nature of school staff' attitudes, the departure from Boulton's study may not be of note.

The findings of the present study suggest that school staff have a commitment to work with both cybervictims and cyberbullies. It has been shown that if school staff are empathetic towards victims, they may be likely to identify bullying, perceive it as serious and may be more likely to implement appropriate strategies (Craig, et al., 2000). Moreover, if school staff hold a belief that cyberbullies can be helped, they may be likely to consider perpetrators in the prevention and intervention of cyberbullying. These findings are relevant when 
considering the vicious cycle of cyberbullying behaviour in that many of those who bully online have themselves been bullied online by others (Raskauskas \& Stoltz, 2007; Smith, et al., 2008; Ybarra, et al., 2006). Thus, cyberbullying can be considered as an issue that damages both victim and perpetrator. In fact, it has been found that both victims and bullies tend to be more psychologically vulnerable than students who are not involved in cyberbullying (Ybarra et al., 2007; Ybarra et al., 2006). Therefore, it is essential, for teachers and senior managers, to consider cybervictims and cyberbullies in order to prevent and address cyberbullying in schools.

\subsubsection{Responsibility}

The findings of the present study suggest that most school staff felt moderately responsible for addressing cyberbullying. Results of the exploratory factor analysis showed that the structure of the factor 'Responsibility' for senior managers differed slightly from the teachers group. In particular, two items (i.e., 'Teachers should help students deal with cyberbullying within the school' and 'Students who are cyberbullied need help to ensure the cyberbullying stops') were added to form the first factor for senior managers and one different item (i.e., 'It is the responsibility of ALL school staff to stop cyberbullying') was added to form the first factor for teachers. These results suggest that senior managers wanted teachers to help students deal with cyberbullying, while teachers wanted all school staff to take responsibility to stop it. It is unclear why the statement 'Students who are cyberbullied need help to ensure the cyberbullying stops' was part of the 'Responsibility' factor for senior managers but not for teachers.

Qualitative data showed that a significant proportion of school staff felt that they were not the only responsible adults for addressing cyberbullying because most of the time it takes place outside school grounds. These findings confirmed Boulton's 1997 study in that teachers were less responsible for preventing bullying outside of school than in the classroom or in the playground (Boulton, 1997). In addition, the findings of the current study supported Mannix and Moynihan's study (2010) that examined teachers' motivation to intervene in cyberbullying incidents. These authors found that many teachers were unsure of their role and felt that it was not part of their responsibility as this type of bullying mostly occurs outside of school hours (Mannix \& Moynihan, 2010).

On the other hand, the findings of the current study differed to a degree from the literature. The 2009 study by Cross et al., explored the perceived role of school staff in taking responsibility for preventing covert bullying. That study found the vast majority of staff saw 
themselves as having responsibility to prevent covert bullying and assist students who were being covertly bullied (Cross et al., 2009). However, Cross et al.'s study did not ask for school staff's perceptions of their responsibility to address covert bullying within and outside of the school. Therefore, it is not surprising that participants of Cross et al.'s study perceived themselves as highly responsible in addressing covert bullying. Even though cyberbullying behaviour may occur outside the school (e.g., students' home computers), it was found that most of the victims knew the perpetrators were from their school (Smith, et al., 2008). In addition, the motivation to engage in cyberbullying behaviours may have had its genesis within the school and the impact of the cyberbullying behaviour may have infiltrated the relationships within the school (Mannix \& Moynihan, 2010). School staff have a key role in addressing cyberbullying regardless of where it takes place because they must guarantee a safe learning environment for their students.

\subsection{Summary}

This study provided valuable data on the ecological phenomenon of covert bullying by examining teachers' and senior managers' perceptions and attitudes towards the specific issue of cyberbullying. To the author's knowledge, prior to this study no research had been conducted examining the differences between teachers' and senior managers' views on cyberbullying. This study's findings indicated that school staff were concerned about cyberbullying, held positive attitudes towards cybervictims and they held a belief that cyberbullies should be helped. However, school staff, especially senior managers, were not fully aware of cyberbullying occurrence within their schools. Moreover, school staff were unlikely to identify social exclusion as being a component of cyberbullying and they felt only moderately responsible for preventing cyberbullying as it commonly occurs outside $t$ school grounds.

\subsection{Methodological contributions to the field}

Two main methodological contributions emerged from this study. First, an exploratory factor analysis (EFA) was conducted to evaluate whether groups of items of the survey used in this study assessed distinct attitudinal constructs (factors) because little research has addressed this area. The authors of the surveys adapted and used in this study did not report any EFA. Results from the EFA in the current study indicated that attitudes towards cyberbullying was a multi-dimensional construct composed of three factors (i.e., 'Concern', 'Empathy' and 'Responsibility'). It is important to note that the factor structure for senior managers differed slightly from the teachers group. However, results of the EFA 
are valuable to determine the potential usefulness of the survey and to inform practitioners as they seek to develop intervention procedures that target specific attitudes towards cyberbullying.

Second, the present study contributes to the field by exploring new populations and relationships. This study is one of the first that has aimed to explored cyberbullying issues through the lens of in-service school staff instead of pre-service teachers. Moreover, to the author's knowledge this is the first study conducted in New Zealand to examine school staff's perceptions and attitudes towards cyberbullying. In addition, it appears that it is the first study that has attempted to compare teachers' and senior managers' views on cyberbullying.

\subsection{Limitations and further research}

According to Johnson and Christensen (2008) self-report questionnaires, such as the one used in this study, might present some limitations. First, even though we assured anonymity to the respondents, respondents may have tried to show only what is socially desirable. The second limitation is the low response rate. There are several possible reasons for this. One possibility is that the survey was sent out at an inconvenient time for schools (November). Another possibility is that due to the holiday break, it was not possible to send follow up email reminders to those that did not respond, which could have increased the response rate. An additional possibility is that as bullying/cyberbullying is a sensitive topic, and almost half of the sample was composed by senior managers, it is possible that many principals did not forward the survey to their teachers. It is also fair to assume that only the more interested and well-informed teachers replied to the survey rather than a cross section of teachers. Despite the low response rate, it is important to highlight the value of this study of being the first one in attempting to survey in-service teachers as well as senior managers about cyberbullying.

Based on the findings of this study, six recommendations for future research were formulated. First, results from the EFA, indicated that 'attitudes towards cyberbullying' was a construct with different factor structure for teachers and senior managers. Future research could identify clear factors for the overall sample (i.e., teachers and senior managers) in order to compare and contrast the two groups on an identical factor structure. Second, the current study used self-report questionnaire to elicit school staff's perceptions and attitudes towards cyberbullying. Future studies could present school staff with realistic situations to assess their views on cyberbullying. Vignettes based on real situations can serve to elucidate attitudes and 
perceptions held by respondents when the topic is sensitive. Third, it is recommended that the next step of research would be to use a larger sample of school staff to be able to have more confidence in the results and to be able to generalize them to other populations. Fourth, it is recommended that further research should focus on cyberbullying prevalence among young students and about the gender of students implicated in cyberbullying from the students' point of view. This will further assist the development of effective response strategies for school staff. Fifth, it is suggested that further research should focus on parents' perceptions and attitudes towards cyberbullying. This is a missing piece in research so far that could assist the development of interventions that target parents. Finally, by using the survey used in the current study, future research would benefit from an examination of the effects of professional development programmes. Follow-up studies could provide useful information about the effectiveness of these programmes and would allow practitioners to develop effective training programmes that target specific attitudes towards cyberbullying.

\subsection{Theoretical and applied implications}

The Social-Ecological Theory, initially developed by Bronfenbrenner (1979), holds that human development is influenced by several environmental systems. Swearer and Espelage (2004) adapted the Social-Ecological Theory in order to explain bullying behaviours. According to Swearer and Espelage (2004), bullying behaviours are the result of complex interactions between individual factors and social environments (i.e., family, peer group, school, community, and culture). Moreover, in recent years the Internet/online environment has begun to be considered as a subsystem of the child social ecology where digital technologies impact on child development (Johnson \& Puplampu, 2008). The student involved in bullying as a bully, victim, or bystander is at the centre of his/her social ecology and is affected by his/her surroundings. The presence of risk factors (e.g., lack of adult monitoring) in any social environment puts a student at higher risk of bullying. By contrast, the presence of protective factors (e.g., positive school climate) may defend the student from bullying behaviours (Hong \& Espelage, 2012).

Since all forms of bullying behaviours are influenced by different social environments, anti-bullying interventions need to target those environments. Whilst all adults in a school community have a role in ensuring students' safety, school staff have the key role in addressing cyberbullying. Since schools are able to reach all students, their parents, and the broader community when creating a safe learning environment, school staff are in a good position to take the lead and responsibility in the prevention of all forms of bullying. One 
effective avenue of intervention to prevent all forms of bullying is the whole-school approach. The first whole-school intervention implemented on a large scale was the Olweus Bullying Prevention Program (Olweus, 1999). Within this program, it is considered essential that all members of school community be informed about what bullying is and how they should respond to it (Olweus, 2004). The following section presents the findings of the current study in light of a whole-school approach to preventing cyberbullying. This wholeschool approach includes interventions at different levels, including individual factors, peer group, family, school, community, culture, and the Internet.

\subsubsection{Individual level}

According to Swearer and Espelage (2004), individual factors of the student implicated in cyberbullying (e.g., gender and age) will influence their participation in cyberbullying. Since results of the present study showed that school staff perceived cyberbullying as being conducted by students across all ages, anti-cyberbullying initiatives should ideally cover primary and secondary schools. Even though cyberbullying has its own characteristics, cyberbullying and traditional bullying should be seen as connected because overt and covert forms of bullying are part of a vicious cycle in which bullies reach their victims through different means (Campbell, 2005). Thus, some of the anti-bullying interventions that are currently being used by schools may be also effective in dealing with cyberbullying incidents.

The anti-bullying initiatives that target individual factors must consider cybervictims, cyberbullies and bystanders in order to be effective (Olweus, 1999). One approach could be the implementation of interventions that provide cybervictims with individual support, counselling and advocacy options (Carroll-Lind, 2009). In addition, steps may be taken to change the attitudes and behaviours of the cyberbullies. For instance, the cyberbully could be required to participate in a restorative conference or attend a specific programme offered by the school in order to develop pro-social skills (Carroll-Lind, 2009). These initiatives could also consider bystanders by encouraging a commitment among students to be a responsible spectator and report cyberbullying incidents to relevant school staff (NetSafe, 2012).

\subsubsection{Family level}

Another factor that influences the development of cyberbullying are parents and home environment (Swearer \& Espelage, 2004). Results of the present study showed that school staff felt moderately responsible for preventing cyberbullying and they wanted more parent involvement to address this issue. A recent study conducted by Livingstone, Haddon, Görzig, 
and Ólafsson (2011) found that parents who guide or monitor their child when $\mathrm{s} / \mathrm{he}$ goes online have children who encounter fewer risks and also less harm over the Internet (Livingstone et al., 2011). However, some parents never do any form of monitoring when their children go online and most parents are not aware of cyberbullying prevalence among their children's peer group (Livingstone et al., 2011).

Thus, school staff may want to consider developing stronger connections between the home and the school to ensure parents and caregivers are aware of how their children use and are affected by their technology (NetSafe, 2012). One approach could be the distribution of information and the implementation of special assemblies or workshops to clarify school antibullying policies. These initiatives may provide parents that don't have technological skills, with digital literacy and safety skills. In addition, home-school interventions could discuss ethical use of technology outside of school, detail who to contact if cyberbullying occurs and explain how to intervene effectively.

\subsubsection{Peer group level}

According to Swearer and Espelage (2004) one of the social environments that affect cyberbullying behaviours is the peer group. If the individual's peer group support bullying, then the individual may be more likely to be involved in those behaviours (Swearer \& Espelage, 2004). Thus, school interventions must focus on improving peer-relations among students in order to prevent all forms of bullying in schools.

Results of the current study showed that most school staff perceived that a low frequency of cyberbullying was occuring in their schools. That suggests that many students may not be reporting cyberbullying to school staff. Thus, interventions that target peer group must consider that one of the first steps is to increase report rates (Campbell, Cross, Spears, \& Slee, 2010; Livingstone et al., 2011). School staff could encourage not only victims, but also bystanders to report all forms of bullying (Netsafe, 2005). In order to increase report rates, school staff may want to consider providing students with knowledge about cyberbullying and the consequences of such behaviours for all involved (Hong \& Espelage, 2012). Students should be made aware of the different available ways to report bullying episodes, including cyberbullying (Carroll-Lind, 2009). In addition, school staff may want to consider providing confidentiality in the process of reporting cyberbullying (Campbell, et al., 2010). 
Classroom interventions could also be implemented in order to improve peer-relations among students. Teachers could develop a clear statement of what is appropriate behaviour in their learning environment (Cleary \& Palmer, 2012). This statement could include appropriate behaviour while using the Internet and mobile phones both inside and outside of school time (Netsafe, 2005).

\subsubsection{School level}

An additional factor that influences cyberbullying participation among students is the school climate (Swearer \& Espelage, 2004). School climate is composed by the perceptions, attitudes and behaviours of the entire school community and can have either a positive or negative effect on all forms of bullying (Doll et al., 2011). If the student attends a school where school staff tolerate bullying behaviours, then the individual may be more likely to be involved in bullying. On the other hand, if school staff hold attitudes not supportive of bullying behaviour, the school becomes less tolerant of bullying and the individual may be unlikely to be involved in that behaviour (Espelage \& Swearer, 2010). The findings of the current study suggest that staff were concerned about cyberbullying, they held positive attitudes towards cybervictims and a belief that cyberbullies should be helped. However, the results of the present study also revealed that some school staff still need to become more aware of cyberbullying and need to have a better understanding of what cyberbullying is, and its prevalence among students. In addition, the results showed that most of the school staff indicated they felt only moderate responsibility to address cyberbullying. However, given the critical role of school staff combating cyberbullying, they may need to take more responsibility to address cyberbullying in order to create a school environment that discourages this behaviour.

In order to change school staff's perceptions and attitudes towards cyberbullying, support, awareness and understanding among school staff must be established. Shifts in school staff's perceptions and attitudes towards cyberbullying will modify their behaviours and in turn the school routines and practices, which can serve as a first line of defence against cyberbullying (Doll, et al., 2011). It has been stated that one way to increase awareness and responsibility among school staff is through the implementation of school anti-bullying policies that cover all forms of bullying in their schools (NetSafe, 2012). Those anti-bullying policies should not only contain reactive responses, but also need to provide safe school environments involving student empowerment and education (Campbell, et al., 2010). Senior managers could also ensure that cyberbullying is addressed as part of the curriculum in 
information and communication technologies and other relevant lessons (Livingstone et al., 2011).

A second way to increase awareness and understanding about cyberbullying among school staff is through professional development programmes (Holt \& Keyes, 2004). Those programmes should create a common understanding among school staff about cyberbullying and its negative effects on students (Cleary \& Palmer, 2012). Results of the present study showed that school staff perceived cyberbullying as conducted by students of all ages, but mainly by girls. Thus, professional development programmes also need to equip school staff with the skills to support all students, especially girls, by using developmentally appropriate practice. Finally, professional development programmes could clarify school anti-bullying policies, inform and implement preventive initiatives and procedures for dealing with all forms of bullying, including episodes that occur out of the school (Cleary \& Palmer, 2012).

\subsubsection{Community level}

The community outside the school is one of the social environments that influence the development of cyberbullying (Swearer \& Espelage, 2004). Within the context of school bullying, the relevant community members are the Ministry of Education, Youth and Child Welfare Services, police and other relevant agencies and organizations that work on the wellbeing of young populations, such as NetSafe (i.e., an organization that promotes safe use of online technologies in New Zealand).

The New Zealand Ministry of Education (2009) stipulates that schools must provide a safe physical and emotional environment. Even though many schools have written policies and procedures for responding to bullying, violence and abuse (Carroll-Lind, 2009), findings of the current study show there is a lack of awareness among some school staff, especially among senior managers, regarding cyberbullying prevalence. Since senior managers have a central role in leading prevention and intervention efforts including implementing antibullying strategies (Mason, 2008), the Ministry of Education may want to encourage awareness raising initiatives among school senior managers. One way to do that is by reviewing existing anti-bullying policies and school behaviour policies so that they cover cyberbullying incidents (NetSafe, 2012).

School senior managers could also work to enhance networking between the school and the broader community. Relevant members of the community could be invited to attend anti-bullying school interventions, professional development programmes and home-school 
activities. These organizations could participate in those initiatives by raising awareness, providing information about the service they provide, offering guidance and effectively supporting students, school staff, parents, and caregivers.

\subsubsection{Culture level}

According to Swearer and Espelage (2004), culture, as part of the student' social environment is a strong predictor of bullying. Culture refers to, for example, cultural beliefs and norms that influence people's behaviours (Bronfenbrenner, 1979). Within the context of culture, aggressive behaviour may be constructed for the purpose of coercion which one exercises against another person (Hong \& Espelage, 2012). Aggressive behaviours and therefore bullying as a subset of these behaviours, can vary by culture. For instance, it has been found that New Zealand has a high rate of bullying when compared to other countries (Carroll-Lind, 2009). Livingstone et al., (2011) state that there is usually a correlation between high rates of bullying with high rates of cyberbullying.

Cultural norms also include the communication practices through which members of a particular culture maintain their relationships. Communication practices are constantly evolving, and students' relationships today are rooted in an online environment. Currently, in New Zealand and other developed countries, students from all age groups are socially connected with others through the Internet and mobile phones. Even though some activities students do online can be beneficial, students also encounter a range of online risks, such as exposure to sexual images, contact with strangers, and involvement in cyberbullying (Livingstone et al., 2011). It has been found that countries such as New Zealand with high rates of technology communications are associated with high online risk (Livingstone et al., 2011). Since features of the New Zealand culture, such as high rate of bullying and high rate of technology communication, increase the likelihood of cyberbullying occurrence among young people, it is imperative to create a culture of care and respect among students in schools.

\subsubsection{Internet/online level}

Johnson and Puplampu (2008) proposed the techno-subsystem as part of the child social ecology environment. It includes child interaction with both living and nonliving elements of communication, information, and recreation technologies in immediate environments. This system overlays and surrounds the existing socio-ecological system interacting with individual, families, schools and workplaces and impacts on the development of childhood (Spears \& Zeederberg, 2012). In fact, it was found that different patterns of 
Internet use differently impact child development. For instance, Livingston et al. (2011) found that even though online risks increases as the Internet use increase, digital literacy also increases with the use of the Internet. Children who use the Internet more have more digital skills to judge the veracity of websites and to manage privacy and personal disclosure (Livingstone et al., 2011).

Since most young people, particularly those in developed countries, are using the Internet for information, entertainment and communication (Livingstone et al., 2011), schools may no longer be the only setting to prevent or address cyberbullying incidents. Spears and Zeederberg (2012), introduce the concept of online social marketing as an emergent intervention strategy which makes use of the Internet to potentially deliver messages designed for preventing cyberbullying to young people. Thus, schools may want to consider employing social media technologies, such as magazines, Internet forums, social networking sites (e.g., Facebook), blogs and microblogs (e.g., Twitter) as Internet platforms to deliver messages especially created for preventing cyberbullying. Those messages could potentially reach students online, which is one of the settings where they are socialising, playing and learning (Spears \& Zeederberg, 2012).

\subsection{Summary}

By viewing the results of the current study within the Social-Ecological Theory, a number of important applied implications have been noted. Since cyberbullying behaviours are largely influenced by individual factors and social environments (i.e., family, peer group, school, community, culture, and the Internet), anti-cyberbullying interventions also need to target those elements by implementing a whole-school approach. The interventions need to cover primary and secondary schools, and it is important to consider cybervictims, cyberbullies, bystanders and peer group to ensure positive peer-relations among students. Accessing young people via online, using social media technologies, is an option that schools may want to consider. Related to that, interventions may include all school staff to ensure positive peer-relations a positive school climate. In addition, anti-cyberbullying initiatives could also focus on enhancing the networking between the school, the home and community members in order to combat cyberbullying from different environments. Thus, it is important to cover the overall culture of the school in order to create an environment that discourages cyberbullying. 


\subsection{Conclusion}

As most young people in developed countries use both the Internet and mobile phones (Kleeb, 2007; Netsafe, 2005), there is an elevated risk of experiencing cyberbullying (Livingstone et al., 2011). Cyberbullying can cause significant emotional harm. It can disrupt children' and adolescents' social development, and it can be associated with negative student outcomes (Kowalski et al., 2008; Marsh et al., 2010). The United Nations Convention on the Rights of the Child recognises a child's right to a safe environment and protection from all forms of physical and emotional harm, including all forms of bullying. Thus, schools must provide students with a safe learning environment, however, schools are challenged with ways to address the phenomenon of cyberbullying.

As has been argued in this thesis, the perceptions and attitudes of school staff need to be taken into consideration, and in some cases modified, if the final aim is to prevent and remove the problem of bullying in all its forms from schools. Evaluations of school staff's perceptions and attitudes will permit the development of targeted school interventions and professional development programmes that will in turn result in school climates that do not tolerate bullying in general and cyberbullying in particular. 


\section{References}

Allport, G. (1935). Attitudes. In Murchison C. (Ed.), Handbook of social psychology (pp. 798- 844). Worcester, MA: Clark University Press.

Bauman, S., \& Del Rio, A. (2006). Preservice teachers' responses to bullying scenarios: Comparing physical, verbal, and relational bullying. Journal of Educational Psychology, 98(1), 219.

Beale, A. V., \& Hall, K. R. (2007). Cyberbullying: What school administrators (and parents) can do. The Clearing House: A Journal of Educational Strategies, Issues and Ideas, 81(1), 8-12.

Belsey, B. (2006). Cyberbullying: An emerging threat to the "always on" generation. Retrieved from http://www.cyberbullying.ca/pdf/Cyberbullying_Article_by_Bill_Belsey.pdf

Boulton, M. J. (1997). Teachers' views on bullying: Definitions, attitudes and ability to cope. British Journal of Educational Psychology, 67(2), 223-233.

Boyatzis, R. E. (1998). Transforming qualitative information: Thematic analysis and code development: Sage Publications, Inc.

Bronfenbrenner, U. (1979). The ecology of human development: Experiments by nature and design: Harvard University Press.

Campbell, M. A. (2005). Cyber bullying: An old problem in a new guise? Australian Journal of Guidance and Counselling, 15(1), 68-76.

Campbell, M. A., Cross, D., Spears, B., \& Slee, P. (2010). Cyberbullying: legal implications for schools (Vol. 118): The Centre for Strategic Education.

Carroll-Lind, J. (2009). School safety: An inquiry into the safety of students at school. Wellington: Office of the Children's Commissioner.

Cleary, M., \& Palmer, G. (2012). Stop bullying!: Guidelines for schools. Retrieved from http://www.police.govt.nz/service/yes/nobully/stop_bullying.pdf

Craig, K., Bell, D., \& Leschied, A. (2011). Pre-service teachers' knowledge and attitudes regarding school-based bullying. Canadian Journal of Education, 34(2), 21-33.

Craig, W. M., Henderson, K., \& Murphy, J. G. (2000). Prospective teachers' attitudes toward bullying and victimization. School Psychology International, 21(1), 5.

Crick, N. R., \& Grotpeter, J. K. (1995). Relational aggression, gender, and socialpsychological adjustment. Child Development, 66(3), 710-722.

Cross, D., Shaw, T., Hearn, L., Epstein, M., Monks, H., and Lester, L.(2009). Australian covert bullying prevalence study (ACBPS). Child Health Promotion Research Centre, Edith Cowan University, Perth.

Doll, B., Song, S., Champion, A., \& Jones, K. (2011). Classroom ecologies that support or discourage bullying. In D. Espelage \& S. Swearer (Eds.), Bullying in North American schools (pp. 147-158). New York: Lwrence Erlbaum Associates, Inc.

Education Counts. (2011). Teacher headcount by designation (grouped), school type and gender in state and state integrated schools, as at April 2011. Retrieved from http://www.educationcounts.govt.nz/statistics/schooling/teaching_staff 
Espelage, D., \& Swearer, S. (2010). A social-ecological model for bullying prevention and intervention: Understanding the impact of adults in the social ecology of youngsters. In S. Jimerson, S. Swearer \& D. Espelage (Eds.), Handbook of bullying in schools: An international perspective (pp. 61-72). New York: Routledge.

Finkelhor, D., Ormrod, R., Turner, H., \& Hamby, S. L. (2005). The victimization of children and youth: A comprehensive, national survey. Child Maltreatment, 10(1), 5.

Hill, M. (2012, May 13). Schools demand powers to search cyber-bullies. Stuff. Retrieved from www.stuff.co.nz

Holt, M., \& Keyes, M. (2004). Teachers' attitudes toward bullying. In D. Espelage \& S. Swearer (Eds.), Bullying in American schools: A social-ecological perspective on prevention and intervention (pp. 121-139). New Yersey: Lawrence Erlbaum Associates, Inc.

Hong, J. S., \& Espelage, D. L. (2012). A review of research on bullying and peer victimization in school: An ecological system analysis. Aggression and Violent Behavior, 17(4), 311-322.

International Association for the Evaluation of Educational Achievement. (2008). Trends in international mathematics and science study (TIMSS 2006/07). Retrieved from http://www.timss.org

Johnson, B., \& Christensen, L. (2008). Educational research: Quantitative, qualitative, and mixed approaches. Thousand Oaks: Sage Publications, Inc.

Johnson, G. M., \& Puplampu, K. P. (2008). Internet use during childhood and the ecological techno-subsystem. Canadian Journal of Learning and Technology, 34(1), 19-28.

Kallestad, J. H., \& Olweus, D. (2003). Predicting teachers' and schools' implementation of the Olweus bullying prevention program: A multilevel study. Prevention \& Treatment, 6(1), 21a.

Kiriakidis, S. P., \& Kavoura, A. (2010). Cyberbullying: A review of the literature on harassment through the Internet and other electronic means. Family \& Community Health, 33(2), 82.

Kleeb, J. (2007). Youth and the internet: The positives, the challenges and New Zealand developments. Wellington: Victoria University of Wellington.

Kowalski, R. M., Limber, S. P., \& Agatston, P. W. (2008). Cyber bullying: Bullying in the digital age: Blackwell Publishing.

Li, Q. (2006). Cyberbullying in schools. School Psychology International, 27(2), 157.

Li, Q. (2008). Cyberbullying in schools: An examination of preservice teachers' perception. Canadian Journal of Learning and Technology, 34(2).

Lindsay, P., \& Norman, D.A. (1977). Human information processing: An introduction to psychology. Harcourt Brace Jovanovich, Inc.

Livingstone, S., Haddon, L., Görzig, A., \& Ólafsson, K. (2011). Risks and safety on the internet: The perspective of European children. Full Findings. LSE, London: EU Kids Online.

Maher, D. (2008). Cyberbullying: An ethnographic case study of one Australian upper primary school class. Youth Studies Australia, 27(4), 8.

Mannix, P., \& Moynihan, S. (2010). Teachers' experiences, perceptions of and skills in addressing cyber bullying in Irish schools. Paper presented at the 2nd Global 
Conference on Bullying. Retrieved from

http://works.bepress.com/patricia_mannixmcnamara/14/

Marsh, L., McGee, R., Nada-Raja, S., \& Williams, S. (2010). Brief report: Text bullying and traditional bullying among New Zealand secondary school students. Journal of Adolescence, 33(1), 237-240.

Mason, K. L. (2008). Cyberbullying: A preliminary assessment for school personnel. Psychology in the Schools, 45(4), 323-348.

McLoughlin, C., Meyricke, R., \& Burgess, J. (2009). Bullies in cyberspace: How rural and regional Australian youth perceive the problem of cyberbullying and its impact. Innovation for Equity in Rural Education, 178.

McQuade, S., Colt, J., \& Meyer, N. (2009). Cyber bullying: Protecting kids and adults from online bullies. Westport: Praeger Publishers.

Ministry of Education. (2009). The National Administration Guidelines (NAGs). Retrieved from www.minedu.govt.nz.

Nansel, T. R., Overpeck, M., Pilla, R. S., Ruan, W. J., Simons-Morton, B., \& Scheidt, P. (2001). Bullying behaviors among US youth. JAMA: the journal of the American Medical Association, 285(16), 2094-2100.

Netsafe. (2005). The text generation: Mobile phones and New Zealand youth. Retrieved from www.netsafe.org.nz

NetSafe. (2012). Cyberbullying information and advice for teachers and principals. Retrieved from http://www.cyberbullying.org.nz/teachers/

Newgent, R. A., Lounsbery, K. L., Keller, E. A., Baker, C. R., Cavell, T. A., \& Boughfman, E. M. (2009). Differential perceptions of bullying in the schools: A comparison of student, parent, teacher, school counselor, and principal reports. Journal of School Counseling, 7, 33.

Novick, R. M., \& Isaacs, J. (2010). Telling is compelling: The impact of student reports of bullying on teacher intervention. Educational Psychology, 30(3), 283-296.

Olweus, D. (1999). Sweden. In P. K. Smith, Y. Morita, J. Junger-Tas, D. Olweus, R.

Catalano \& P. Lee (Eds.), The nature of school bullying: A cross-national perspective (pp. 7-27). London: Routledge.

Olweus, D. (2004). The Olweus bullying prevention programme: Design and implementation issues and a new national initiative in Norway. In P. K. Smith, D. Pepler \& K. Rigby (Eds.), Bullying in schools: How successful can interventions be? (pp. 13-36). Cambridge: Cambridge University Press.

Pallant, J. (2007). SPSS Survival Manual. Buckingham: Open University Press.

Pepler, D. J., Craig, W. M., Ziegler, S., \& Charach, A. (1994). An evaluation of an antibullying intervention in Toronto schools. Canadian Journal of Community Mental Health (Revue canadienne de santé mentale communautaire), 13(2), 95-110.

Pervin, K., \& Turner, A. (1994). An investigation into staff and pupils' knowledge, attitudes and beliefs about bullying in an inner city school. Pastoral Care in Education, 12(3), $16-22$.

Punch, K. (2003). Survey research: The basics. London: Sage Publications Ltd.

Raskauskas, J. (2007). Text-bullying among early adolescents. Massey University, 8(1), 1721. 
Raskauskas, J., \& Stoltz, A. D. (2007). Involvement in traditional and electronic bullying among adolescents. Developmental Psychology, 43(3), 564.

Rigby, K. (1997). Manual for the peer relations questionnaire (PRQ). Point Lonsdale, Victoria, Australia: The Professional Reading Guide.

Smith, P., Mahdavi, J., Carvalho, M., Fisher, S., Russell, S., \& Tippett, N. (2008). Cyberbullying: its nature and impact in secondary school pupils. Journal of Child Psychology and Psychiatry, 49(4), 376-385.

Smith, P., \& Stonje, R. (2010). Cyberbullying: The nature and extent of a new kind of bullying. In and out of school. In S. Jimerson, S. Swearer \& D. Espelage (Eds.), Handbook of bullying in schools: An international perspective (pp. 249-262). New York: Routledge.

Smith, P. K. (1997). Commentary III. Bullying in life-span perspective: What can studies of school bullying and workplace bullying learn from each other? Journal of Community \& Applied Social Psychology, 7(3), 249-255.

Spears, B., Slee, P., Owens, L., Johnson, B. (2009). Behind the scenes and screens: Insights into the human dimension of covert bullying. Journal of Psychology, 217 (4), 189196.

Spears, B., \& Zeederberg, M. (2012). Emerging methodological strategies to adress cyberbullying: Online social marketing and young people as co-researchers. In S. Bauman (ed.) Principles of Cyberbullying Research: Definitions, Measures \& Methodology. Routledge.

Strom, P. S., \& Strom, R. D. (2006). Cyberbullying by Adolescents: A Preliminary Assessment. [doi: 10.1080/00131720508984869]. The Educational Forum, 70(1), 2136.

Swearer, S., \& Espelage, D. (2004). Introduction: Social-ecological framework of bullying among youth. In D. Espelage \& S. Swearer (Eds.), Bullying in American schools: A social-ecological perspective on prevention and intervention (pp. 1-12). New Jersey: Lawrence Erlbaum Associates, Inc.

Trends in International Mathematics and Science Study (TIMSS) (2007). Retrieved from: https://nces.ed.gov/timss/.

United Nations (1989). The United Nations convention on the rights of the child. Geneva: Author. Retrieved from: http://www.unicef.org/crc/fulltext.htm

Vance, A. (2012, May 11). Goverment to crackdown on cyber bullies. Stuff. Retrieved from www.stuff.co.nz

Wang, J., Iannotti, R. J., \& Nansel, T. R. (2009). School bullying among adolescents in the United States: Physical, verbal, relational, and cyber. Journal of Adolescent Health, 45(4), 368-375.

Ybarra, M. L., Diener-West, M., \& Leaf, P. J. (2007). Examining the overlap in internet harassment and school bullying: implications for school intervention. Journal of Adolescent Health, 41(6), S42-S50.

Ybarra, M. L., Espelage, D. L., \& Mitchell, K. J. (2007). The co-occurrence of Internet harassment and unwanted sexual solicitation victimization and perpetration: associations with psychosocial indicators. Journal of Adolescent Health, 41(6), S31S41. 
Ybarra, M. L., \& Mitchell, K. J. (2004). Youth engaging in online harassment: associations with caregiver-child relationships, Internet use, and personal characteristics 1. Journal of Adolescence, 27(3), 319-336.

Ybarra, M. L., Mitchell, K. J., Wolak, J., \& Finkelhor, D. (2006). Examining characteristics and associated distress related to Internet harassment: Findings from the Second Youth Internet Safety Survey. Pediatrics, 118(4), e1169.

Yilmaz, H. (2010). An examination of preservice teachers' perceptions of cyberbullying. Eurasia Journal of Mathematics, Science \& Technology Education, 6(4), 263-270.

Yoon, J., \& Barton, E. (2008). The role of teachers in school violence and bullying prevention. In T. W. Miller (Ed.), School violence and primary prevention (pp. 249275). New York: Springer Science+Business Media, LLC.

Yoon, J. S. (2004). Predicting teacher interventions in bullying situations. Education and Treatment of Children, 27(1), 37-45.

Yoon, J. S., \& Kerber, K. (2003). Elementary teachers' attitudes and intervention strategies. Research in Education, 69, 27-35. 


\section{Appendices}

Appendix A: Information sheet

\section{Online Survey about Bullying in Schools}

\section{Purpose of the study}

Thank you for your interest in our survey. Part 1 contains some basic questions about you (i.e., position in the school, gender, years of experience). Part 2 asks questions related to your perceptions of the prevalence of different forms of bullying in your school. Part 3 gathers information about your perceptions of anti-bullying strategies adopted by your school. Part 4 contains questions about your perceptions and attitudes towards the specific issue of cyberbullying

\section{Completing the Survey}

You cannot proceed to the survey until you indicate you are aware of your rights as a participant. Therefore, should you decide to participate in this study you may access the anonymous survey under the "Giving of Consent" section below. You may skip any questions you do not wish to answer. If you do not want to continue just close your browser.

\section{Participation and Withdrawal}

Your decision to participate in this survey is completely voluntary and you have the right to withdraw your participation at any time before you complete and submit your responses. Your decision about whether to participate will not affect your relationship with Victoria University of Wellington.

\section{Confidentiality, Data Storage, and Deletion}

Your participation in this survey will be completely anonymous. In addition, your school will not be identified and you will not be associated with your school. The data will be reported in aggregate, representing averages or generalizations about the responses as a whole. Once the survey has been closed the information provided in the survey will be downloaded onto computers belonging to the investigators of this study. These files will be password protected, and only accessed by the research team. As required by Human Ethics Policy, the data will be 
stored for 5 years after publication and then destroyed. We will request that Qualtrics Survey Software destroy the data on their system once we have retrieved the information we require.

\section{Ethics}

This research has been assessed and approved by Victoria University Faculty of Education Ethics Committee (Reference number: SEPP/2011/76:RM18902). If at any time you have questions or concerns about your treatment as a research participant in this study, contact Dr Judith Loveridge, who is the current Chair of the Ethics Committee (telephone: $+6444636028)$.

\section{Reporting / Dissemination}

The results from this survey will be submitted as theses and presented in educational settings and at professional conferences. In addition, the results will be submitted for publication in professional journals. Copies of the theses and any publications will be accessible on the VUW Education Website:

http://www.victoria.ac.nz/education/schools/educational-psychology-andpedagogy/default.aspx

If you wish to receive a personal copy of the results found from this survey, please contact Associate Professor Vanessa Green.

\section{Questions about the study}

If you have questions or concerns during the time of your participation, or after its completion, please contact:

Associate Professor Vanessa Green,

School of Educational Psychology and Pedagogy

Faculty of Education

Victoria University of Wellington

PO Box 17-310, Karori

Wellington, NZ 
044639574

Vanessa.green@vuw.ac.nz

Thank you!

Vanessa Green Loreto Mattioni Tessa Prior

\section{Giving of Consent}

o I have read this information page and agree to participate in this study, with the knowledge that I am free to withdraw my participation at any time without penalty. 
Appendix B: Online Survey 'Bullying in Schools'

The current study focused on two sections of this survey (i.e., section one and section four).

\section{Instructions for completing the survey:}

- Answer each question by clicking on the button that best reflects your answer.

- You may skip any question or change your answer(s) any time up until the time you press the Submit button at the end of the survey.

- To deselect an answer, you may double click your selection.

- After you complete each section, click on the Next button at the bottom of the page.

- You can go back to change your answers by clicking on the Previous button at the bottom of the page.

- You can save your responses at any time and return to the survey later.

- When the survey is complete, submit your answers by clicking the Submit button at the bottom of the page.

Section One - Demographics:

1.- What position do you hold in your school?

C Principal/ Deputy Principal

C Dean

C Head of Department

E Teacher 
2. How many years have you worked in schools?

C Less than 1 year

C 2-6 years

C 7-14 years

D 15- 20 years

[20+

3. What is your gender?

C Female

C Male

4. What is your type of school?

C Primary

C Intermediate

C Secondary

C Primary through Secondary

C Intermediate through Secondary

5. Which year level do you teach this year (if any)? If you teach across year levels please indicate each year:
$\ulcorner\quad$ Year 5
$\Gamma \quad$ Year 6
$\Gamma \quad$ Year 7 
$\Gamma \quad$ Year 8

$\Gamma \quad$ Year 9

$\Gamma \quad$ Year 10

Г Year 11

Г Year 12

Г Year 13

Г $\mathrm{N} / \mathrm{A}$

6. What sector is your school?

C Public / state

C Integrated school (i.e., significant government funding)

C Kura Kaupapa Maori

$\mathbf{C}$ Private / independent (i.e., minimum government funding)

7. Is your school:

C Co-educational

E All male

C All female

8. What decile is your school? 
Following are the definitions for bullying with descriptions and examples of each subtype of bullying.

A definition of bullying is that "a student is being bullied or victimized when he or she is exposed, repeatedly and over time, to negative actions on the part of one or more other students" (Olweus, 1999, p. 10). Olweus (1999) adds that bullying is based on an asymmetric power relationship.

Bullying can take many forms. Often they are divided into two groups:

A. Overt Bullying is done face-to-face and includes:

1.- Physical: Being physically aggressive towards others (i.e., hitting, kicking, pushing, damaging or stealing someone's property).

2.- Verbal: Being verbally aggressive towards others (i.e., hurtful, teasing, insulting, humiliating or threatening someone).

B. Covert Bullying is not easily seen by adults or others and includes:

1.- Social/Relational: Being socially aggressive towards others (i.e., deliberate exclusion of someone from 'the group' or from an activity, spreading rumors about someone).

2.- Cyber: The use of technology to support deliberate hostile behaviour by an individual or group, that is intended to harm others.

C I have read the above definitions

Section Two - Prevalence

1. Is there bullying at your school?

$\boldsymbol{C}_{\mathrm{Nes}}$
$\boldsymbol{C}_{\text {Don't Know }}$ 
2. Based on your personal experience and perspective, indicate the extent to which you agree or disagree with each of the following statements about bullying at your school by checking ONE response for each statement:

$\begin{array}{lcccc}\text { Strongly } & \text { Disagree } & \begin{array}{c}\text { Neither Agree } \\ \text { nor Disagree }\end{array} & \text { Agree } & \text { Strongly } \\ \text { Disagree } & & \text { Agree }\end{array}$

a) Physical bullying is a problem among

E

$\mathbb{E}$

C

C

C

students at our school

b) Verbal bullying is a problem among

C

E

C

C

students at our school

c) Social/ Relational bullying is a problem among students at our

C

C

C

C

school

d) Cyberbullying is a problem among

C

E

G

E students at our school

3. Based on your personal experience and perspective, think about the past four weeks, then indicate the frequency with which the following types of bullying are brought to your attention by checking ONE response for each statement:

$\begin{array}{cccc}\text { Not once in } 4 & \begin{array}{c}\text { Once or } \\ \text { twice in } 4\end{array} & \text { Once a week } & \text { More than } \\ \text { weeks } & \text { once per } & \text { Don`t know } \\ & \text { weeks } & \text { week } & \end{array}$
a) Physical bullying
C
G
E
E
E
b) Verbal bullying
E
C
C
C
C
c) Social/ Relational
bullying
C
C
E
C
C
d) Cyberbullying
E
C
E
E
C 
Section Three - Bullying Prevention Strategies

4. Do you currently have an anti-bullying strategy in your school?

(If no or don't know, please skip to question 6).

C Yes

C No

C Don't know

5. If you answered "Yes" to Q.4., do you believe the anti-bullying strategy in your school covers the issue of:

\begin{tabular}{|c|c|c|c|c|}
\hline & & Neither & & \\
\hline $\begin{array}{l}\text { Strongly } \\
\text { Disagree }\end{array}$ & Disagree & Agree nor & Agree & $\begin{array}{l}\text { Strongly } \\
\text { Agree }\end{array}$ \\
\hline
\end{tabular}
a) Physical bullying
C
G
E
E
b) Verbal bullying
E
E
E
E
E
c) Social/ Relational bullying
E
E
$\mathbb{E}$
G
E
d) Cyberbullying
C
E
G
G
G

6. Please indicate below the statement which best describes who you believe should be involved in an anti-bullying strategy:

C The entire school (i.e., including teachers, management and support staff)

C The entire school and community

C Only teachers

C Only those teachers who have issues in their classroom

C Only individuals who are perpetrators or victims 
7. Following is a list of general strategies commonly used in schools, please indicate if one or more of the following strategies is implemented by your school:

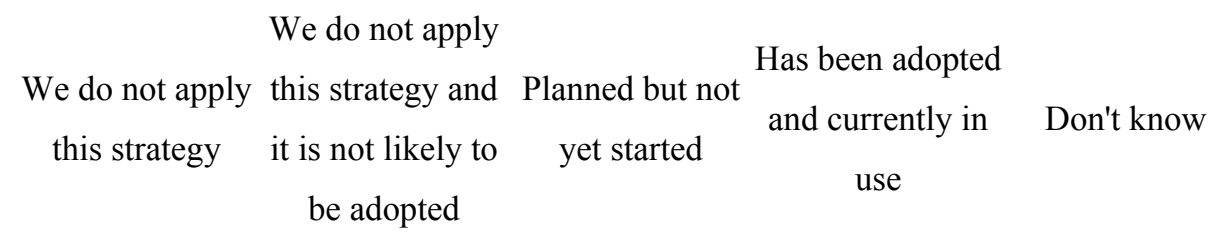

a) Visual displays such as posters and pamphlets on

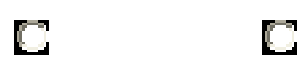
anti-bullying techniques

b) Staff supervision at lunchtimes, before and after school

c) Confiscating electronic devices when not used in accordance with school policy

d) Staff training to facilitate what actions to take when confronted with bullying situations

e) Principal and senior staff commitment to anti-bullying strategies

f) Peer mediation

$$
\text { C }
$$

E

E

C

C

g) Outside help such as a psychologist or counselor usually $\begin{array}{lllll}\text { C } & \text { C } & \text { C } & \text { C } & \text { C }\end{array}$ working with the children involved in bullying 


\begin{tabular}{cccc}
\multicolumn{3}{c}{ We do not apply } & Has been adopted \\
We do not apply this strategy and & Planned but not & and currently in & Don't know \\
this strategy & it is not likely to & yet started & use \\
be adopted & &
\end{tabular}

incidents
h) Kia Kaha
E
E
E
E
C

i) Consultation

with the whole

school community

(e.g., staff,

students and

C

E

E

C

parents) on the

anti-bullying

movement at your

school

j) A contract with

$\mathbb{C}$

C

the perpetrator

k) No phones

during school

C

C

C

hours policy

1) Class

discussions on

how to prevent

C

bullying

m) Cool Schools

C

C

C

C

C

n) An anti-

bullying video

C

E

E 
8. Please indicate the extent to which you think ANY anti-bullying strategies currently in place at your school are having the following results by checking ONE response for each statement:

$\begin{array}{lcccc}\text { Strongly } & & \text { Neither } & & \text { Strongly } \\ \text { Disagree } & \text { Disagree } & \text { Agree nor } & \text { Agree } & \text { Agree } \\ & & \text { Disagree } & & \end{array}$

a) There is greater understanding by students about the nature of bullying since the implementation of anti-bullying strategies

b) There is greater understanding by teachers about the nature of bullying among students since the implementation of anti-bullying strategies

c) The number of reported bullying incidents has decreased from the use of one or more strategies

d) The atmosphere at our school is generally more positive and peaceful since the

C

C

C

C
G

C

C

C
G

C

$\mathbb{C}$ implementation of anti-bullying strategies

9. Is there a statement on zero tolerance for bullying mentioned in your schools code of conduct?
C Yes
C No
C Not Sure 
10. Have you ever had any training or attended a work-shop for any anti-bullying programmes?

C Yes (Please, provide details)

C No

11. Please indicate below whether you believe anti-bullying guidelines should become part of the national administration guidelines making it compulsory in schools?

C Strongly Disagree

C Disagree

C Neither Agree nor Disagree

C Agree

C Strongly Agree

Section Four- Cyberbullying

12. Based on your personal experience and perspective, which of the following behaviours (if they happened repeatedly) do you consider to be cyberbullying?
Yes
No
Don't know

a) Students sending threatening emails

C

C

C

b) Students sending nasty messages on the

C

C

C internet

c) Students sending nasty text message to others students' mobile phones

d) Students sending nasty or prank calls to other students' mobile phones 
e) Students using other students' screen names or passwords to pretend to be them, and to hurt them

f) Students sending other students' private emails, messages, pictures or videos to others without permission

g) Students sending or posting nasty comments or pictures about other students to websites (e.g., on Facebook)

h) Students deliberately ignoring or leaving others out of events over the internet

i) Students filming physical or verbal abuse and uploading it onto the world wide web via sites such as YouTube

13. Based on your personal experience and perspective is cyberbullying conducted by:

C Mainly boys

Equal numbers of boys and girls

C Mainly girls

14. Based on your personal experience and perspective is cyberbullying conducted by:

C Mainly children (9-10 years old) 
C Mainly younger adolescents (11-14 years old)

C Mainly older adolescents (15-18 years old)

C Students across all age groups

15. Do you think teachers need training to deal with and counteract the effects of cyberbullying?
C Yes
$\square$ No
C Not Sure

16. Based on your personal experience and perspective, please indicate the extent to which you agree or disagree with each of the following statements about cyberbullying behaviour:

\begin{tabular}{|c|c|c|c|c|}
\hline & & Neither & & \\
\hline Disagree & Disagree & & Agree & Agree \\
\hline
\end{tabular}
a) Students are
affected by
$\mathrm{C}$
$\mathbf{C}$
C
C
C
cyberbullying
b) I am concerned about cyberbullying
C
C
E
E
E
c) Cyberbullying
toughens students up
C
C
G
G
d) It's up to parents, not teachers, to teach their children how to
E
E
$\mathbb{E}$
E
respond to
cyberbullying
e) It makes me angry when students are
cyberbullied
f) Students who
cyberbully are unlikely
to change their
behaviour
E
C
C
C $\quad$ C 
Strongly

Disagree

Neither

Disagree Agree nor

Agree

Strongly

Disagree

Agree

g) Students who are

cyberbullied need help

E

E

E

E

to ensure the

cyberbullying stops

h) Cyberbullying is a part of school life

C

which should be

accepted

i) Teachers should

help students deal with

C

C

C

E

cyberbullying within

the school

j) Teachers should

help students deal with

cyberbullying outside

of the school

k) Students who are cyberbullied usually

deserve what they get

C

C

C

C

1) It is the

responsibility of ALL

school staff to stop

cyberbullying

$\mathrm{m})$ Punishment is the best way to respond to a student who is

C

C

C

C

cyberbullying others

n) Students who

cyberbully others

should be spoken to by school staff about their

C

C

C

E

C

behaviour and given

the opportunity to

change

o) Students who are cyberbullied should learn to cope with it on

C

C

C

C

$\mathbb{C}$ their own 


\begin{tabular}{|c|c|c|c|c|}
\hline & & Neither & & \\
\hline $\begin{array}{l}\text { Strongly } \\
\text { Disagree }\end{array}$ & Disagree & Agree nor & Agree & $\begin{array}{l}\text { Strongly } \\
\text { Agree }\end{array}$ \\
\hline
\end{tabular}

p) Teachers should do more to prevent

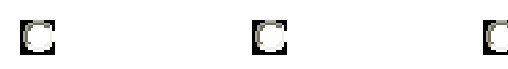

E

⿷

cyberbullying from

happening

q) Cyberbullying is usually more hurtful than overt (face to face) bullying

r) Cyberbullying is harder to stop than overt bullying

s) Teachers should respond in the same way for overt bullying and cyberbullying by students

E $\quad$ C $\quad$ C $\quad$ C $\quad$ C
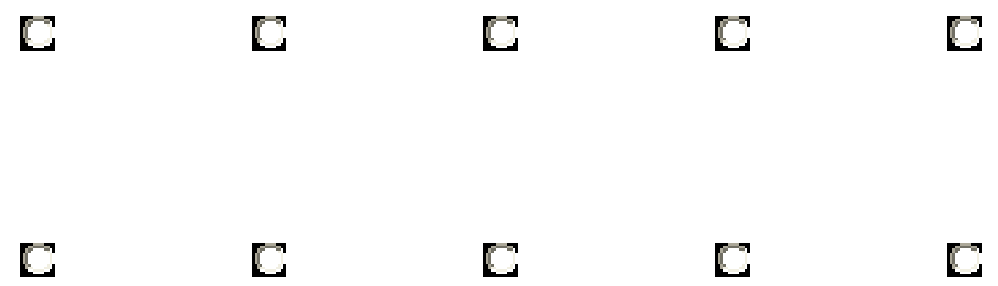

If you have any further comments, please share them below:

Copies of the theses and any publications will be accessible on the VUW Education Website. If you wish to receive a personal copy of the results found from this survey, please contact:

Associate Professor Vanessa Green,

School of Educational Psychology and Pedagogy

Faculty of Education

Victoria University of Wellington

PO Box 17-310, Karori

Wellington, NZ

044639574

Vanessa.green@vuw.ac.nz 


\section{Acknowledgements}

This survey has been compiled by utilizing and adapting the following currently available resources.

- Section One:

Child Health centre survey

Cross, D., Shaw, T., Hearn, L., Epstein, M., Monks, H., Lester, L., et al. (2009). Australian covert bullying prevalence study (ACBPS). Child Health Promotion Research Centre, Edith Cowan University, Perth.

- Section Two:

School Climate Survey

The Ontario Ministry of Education, 2009

- Section Four:

Teachers Perceptions about Cyber bullying Questionnaire (Li, 2008)

The Peer Relations Assessment Questionnaire Form C (Rigby, 1998; adapted by Cross et al, 2009) .

\section{References}

Olweus, D. (1999). Sweden. In P. K. Smith, Y. Morita, J. Junger-Tas, D. Olweus, R. Catalano \& P. Lee (Eds.), The nature of school bullying: A cross-national perspective (pp. 727). London: Routledge.

Thank you for taking the time to complete this survey 
Table C1: Behaviours that constitute cyberbullying

\begin{tabular}{|c|c|c|c|}
\hline \multirow{3}{*}{$\begin{array}{l}\text { Which of the following behaviours do you consider } \\
\text { to be cyberbullying? }\end{array}$} & \multicolumn{3}{|r|}{ Don't } \\
\hline & Yes & No & know \\
\hline & \multicolumn{3}{|c|}{ Percent } \\
\hline Students sending threatening emails & 86.30 & 1.40 & 2.70 \\
\hline Students sending nasty messages on the internet & 86.80 & 0.90 & 2.70 \\
\hline $\begin{array}{l}\text { Students sending nasty text message to others students' } \\
\text { mobile phones }\end{array}$ & 86.30 & 1.80 & 2.30 \\
\hline $\begin{array}{l}\text { Students sending nasty or prank calls to other students' } \\
\text { mobile phones }\end{array}$ & 84.50 & 2.70 & 3.20 \\
\hline $\begin{array}{l}\text { Students using other students' screen names or passwords } \\
\text { to pretend to be them, and to hurt them }\end{array}$ & 85.40 & 2.30 & 2.70 \\
\hline $\begin{array}{l}\text { Students sending other students' private emails, } \\
\text { messages, pictures or videos to others without permission }\end{array}$ & 81.70 & 2.70 & 5.90 \\
\hline $\begin{array}{l}\text { Students sending or posting nasty comments or } \\
\text { pictures about other students to websites (e.g., on Facebook) }\end{array}$ & 86.80 & 1.40 & 1.80 \\
\hline $\begin{array}{l}\text { Students deliberately ignoring or leaving others } \\
\text { out of events over the internet }\end{array}$ & 58.40 & 18.30 & 13.70 \\
\hline $\begin{array}{l}\text { Students filming physical or verbal abuse and } \\
\text { uploading it onto the www via sites such as YouTube }\end{array}$ & 84.00 & 3.20 & 3.20 \\
\hline
\end{tabular}


Table C2: Frequency of school staff responses

\begin{tabular}{ccc}
\hline \multirow{2}{*}{$\begin{array}{c}\text { 'Students who cyberbully are unlikely } \\
\text { to change their behaviour' }\end{array}$} & $\begin{array}{c}\text { Penior manager } \\
(\mathrm{n}=102)\end{array}$ & $\begin{array}{c}\text { Teacher } \\
(\mathrm{n}=90)\end{array}$ \\
\hline Strongly agree & 0 & 2 \\
Agree & 10 & 10 \\
Neither agree nor disagree & 26 & 25 \\
Disagree & 49 & 44 \\
Strongly disagree & 17 & 9 \\
\hline
\end{tabular}

Table C3: Frequency of school staff responses

\begin{tabular}{lcc} 
& \multicolumn{2}{c}{ Position } \\
\cline { 2 - 3 } 'Punishment is the best way to respond \\
to a student who is cyberbullying others' & $\begin{array}{c}\text { Senior } \\
\text { manager } \\
(\mathrm{n}=103)\end{array}$ & $\begin{array}{c}\text { Teacher } \\
(\mathrm{n}=90)\end{array}$ \\
\hline Strongly agree & 4 & 3 \\
Agree & 7 & 8 \\
Neither agree nor disagree & 27 & 35 \\
Disagree & 51 & 31 \\
Strongly disagree & 14 & 13 \\
\hline
\end{tabular}


Appendix D: Histograms

Figure 1. School staff's frequency histogram of 'Cyberbullying is a problem among students at our school'

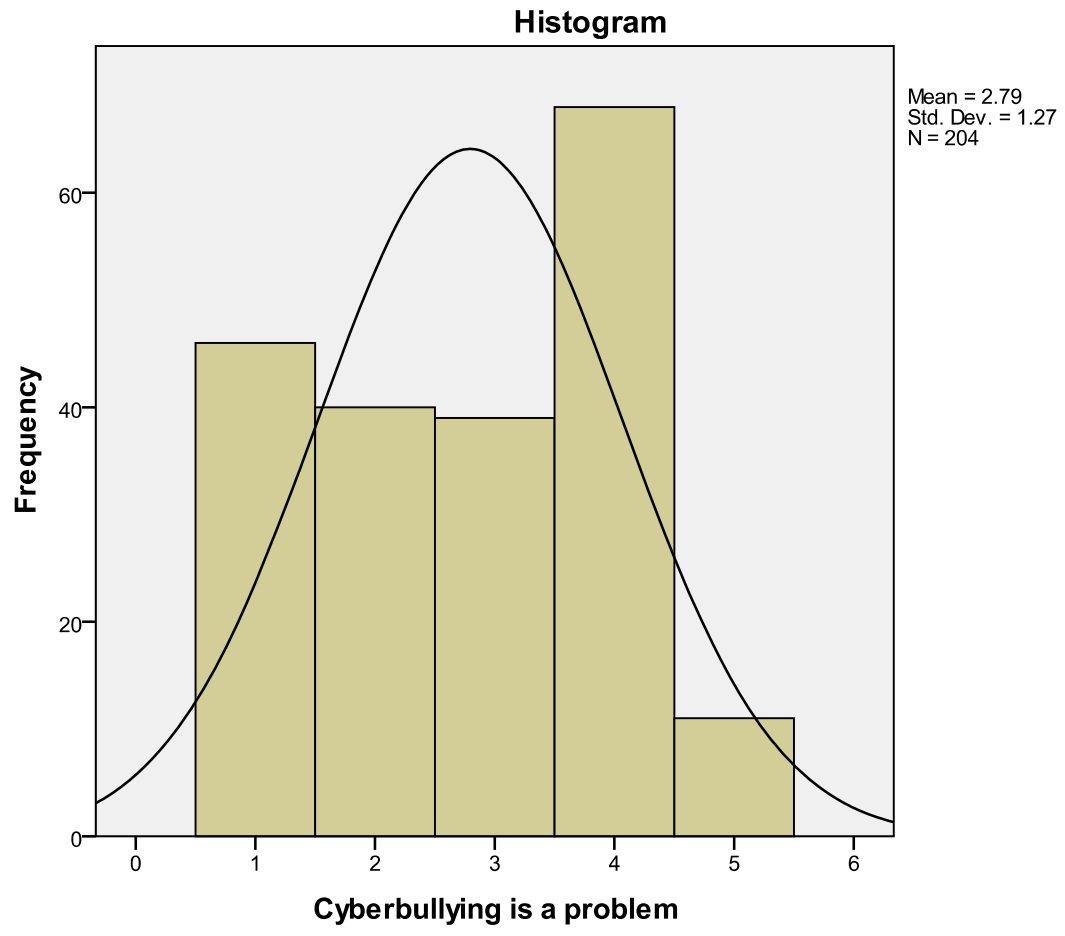

Figure 2. Teachers' frequency histogram of Factor 1 (Responsibility)

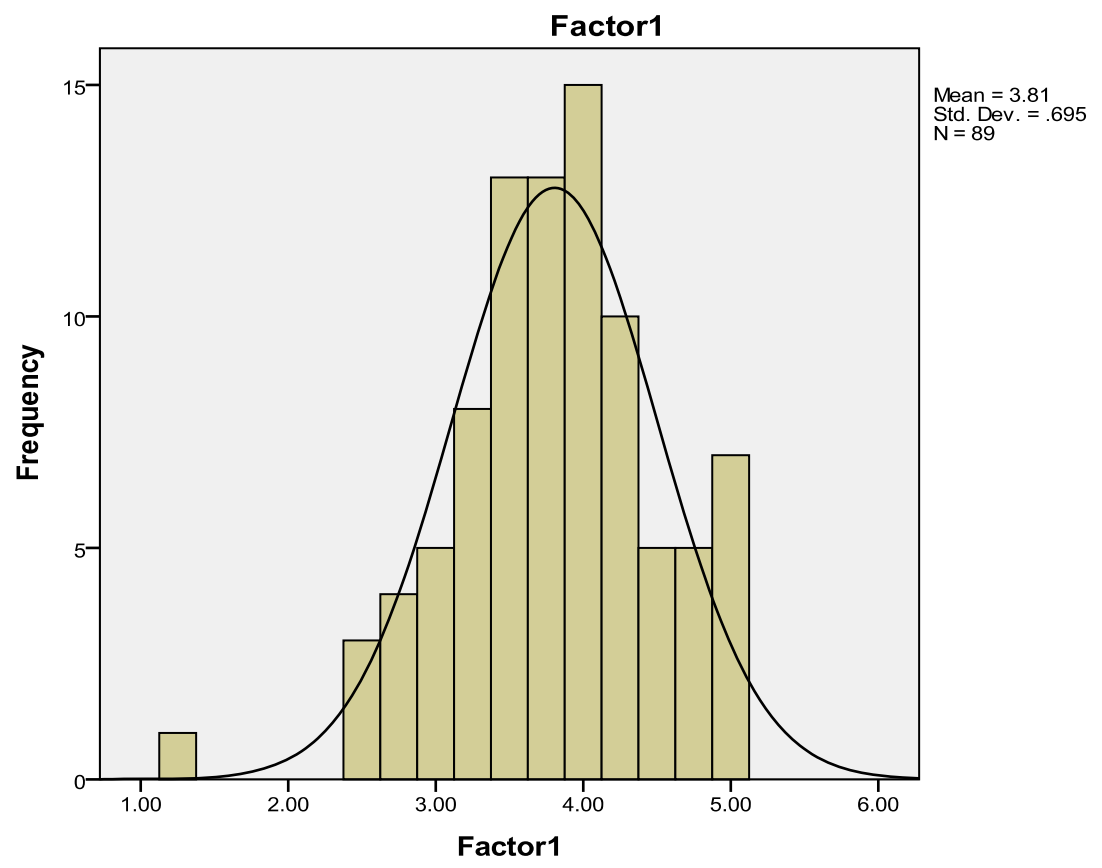


Figure 3. Teachers' frequency histogram of Factor 2 (Empathy)

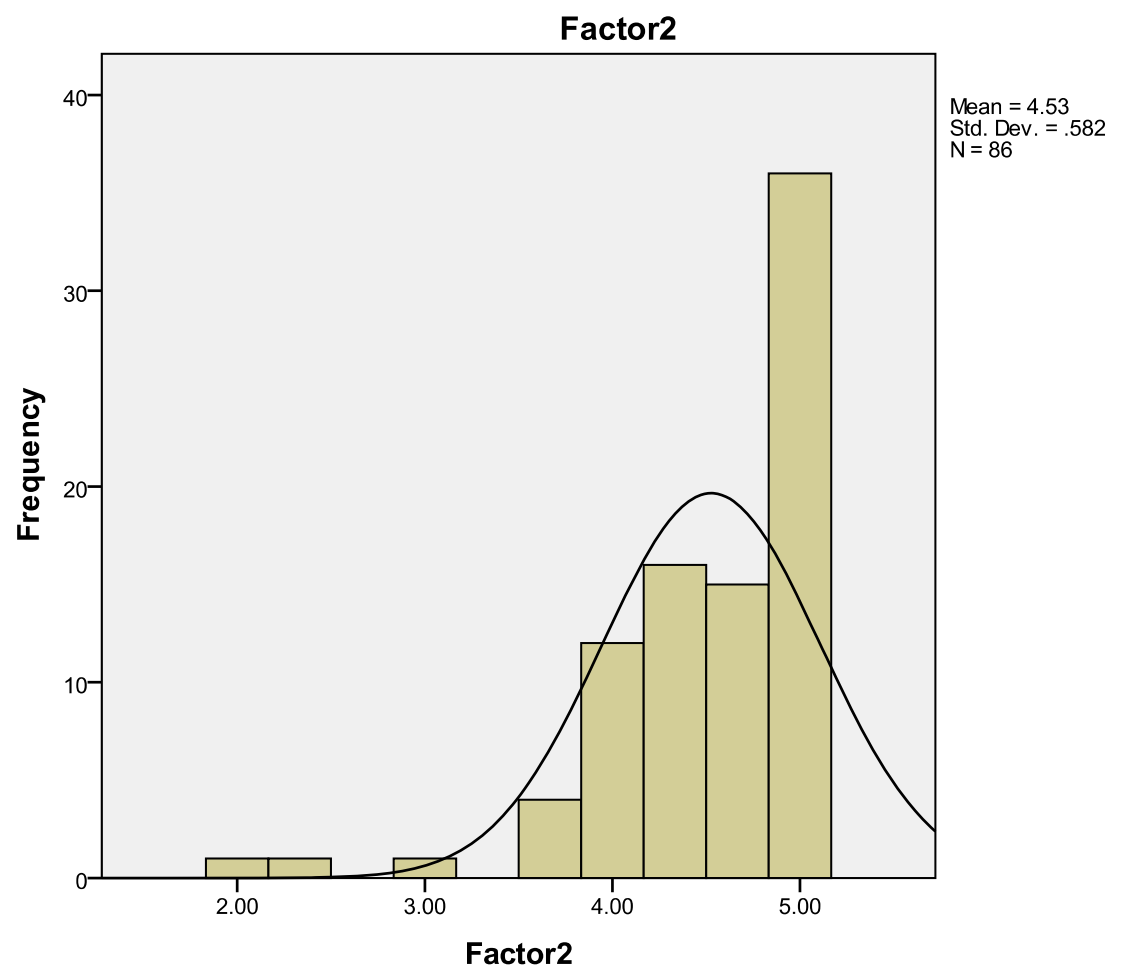

Figure 4. Teachers' frequency histogram of Factor 3 (Concern)

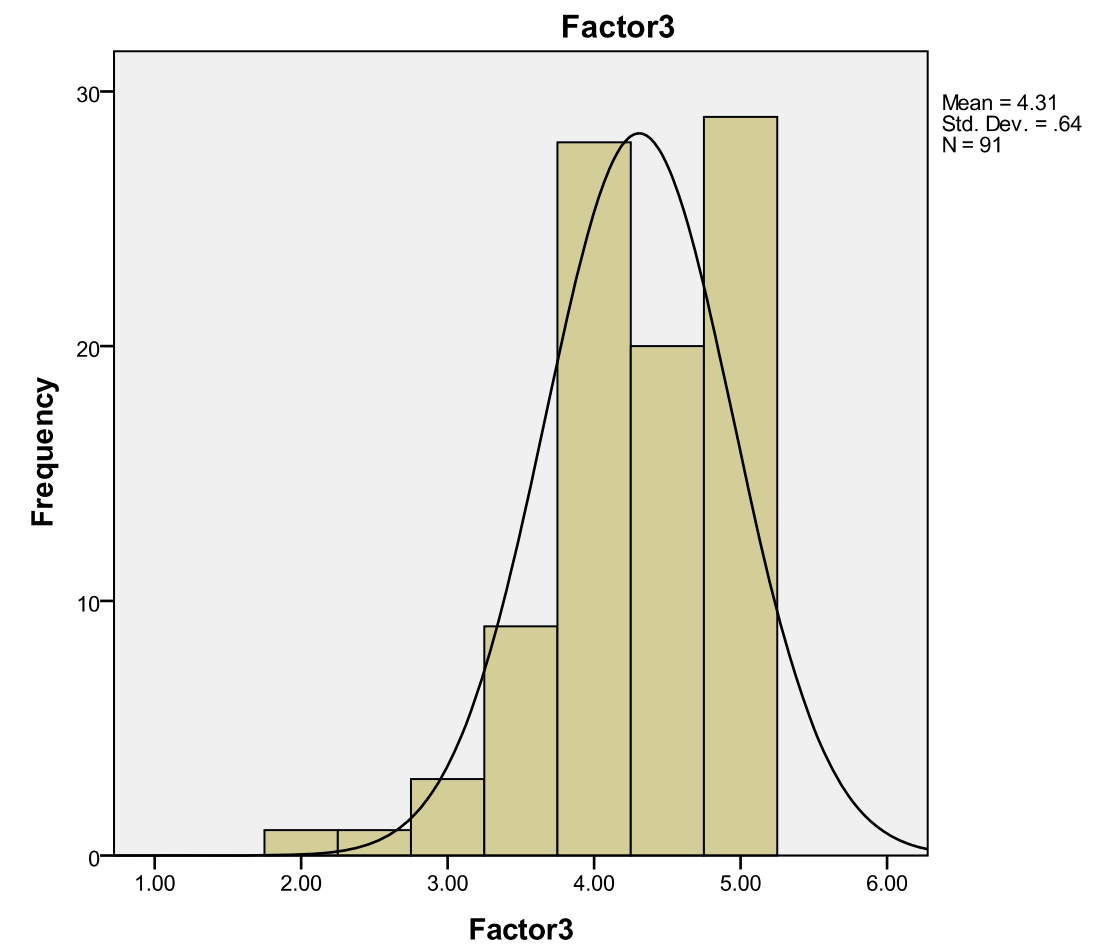


Figure 5. Senior managers' frequency histogram of Factor 1 (Responsibility)

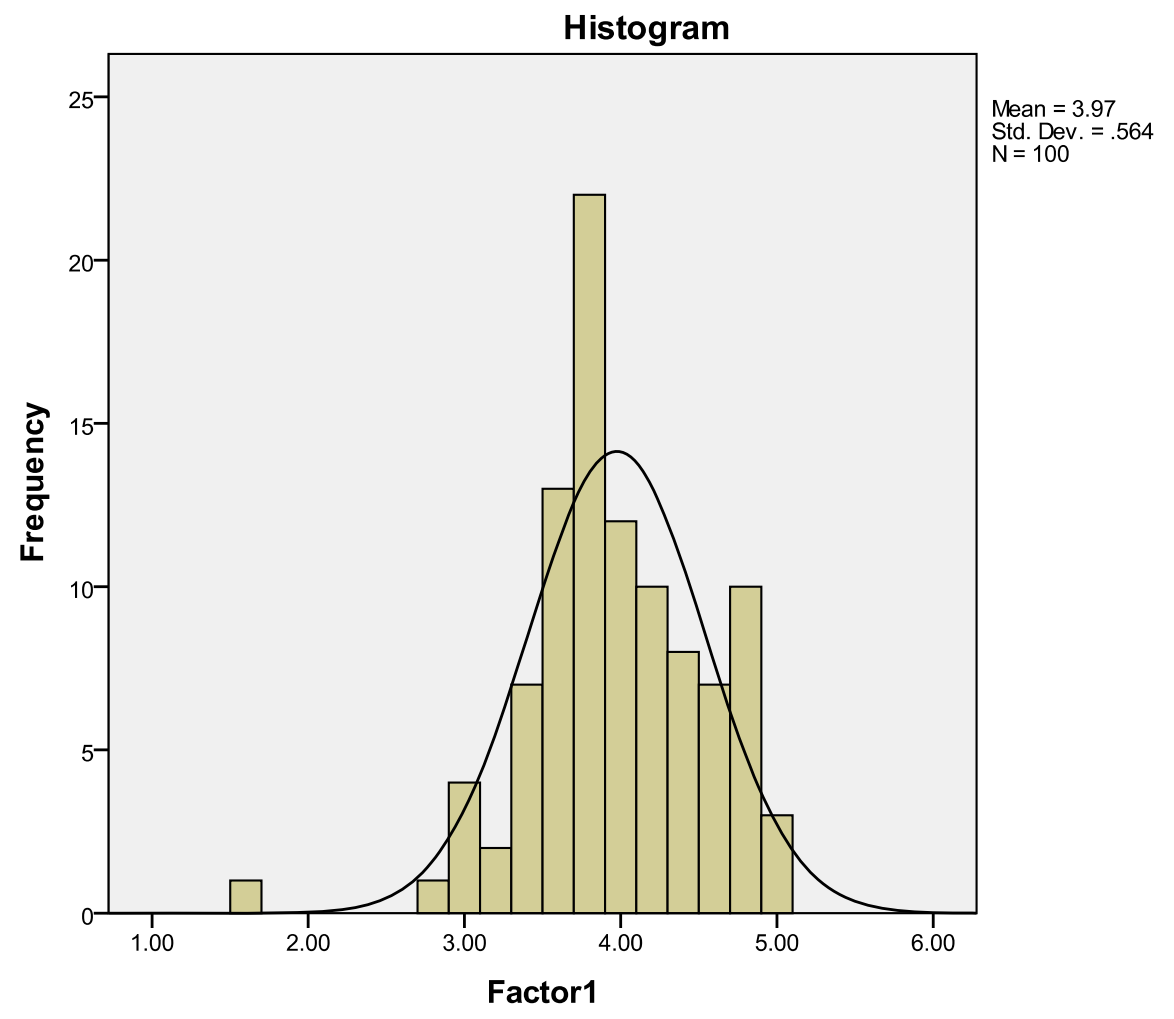

Figure 6. Senior managers' frequency histogram of Factor 2 (Empathy)

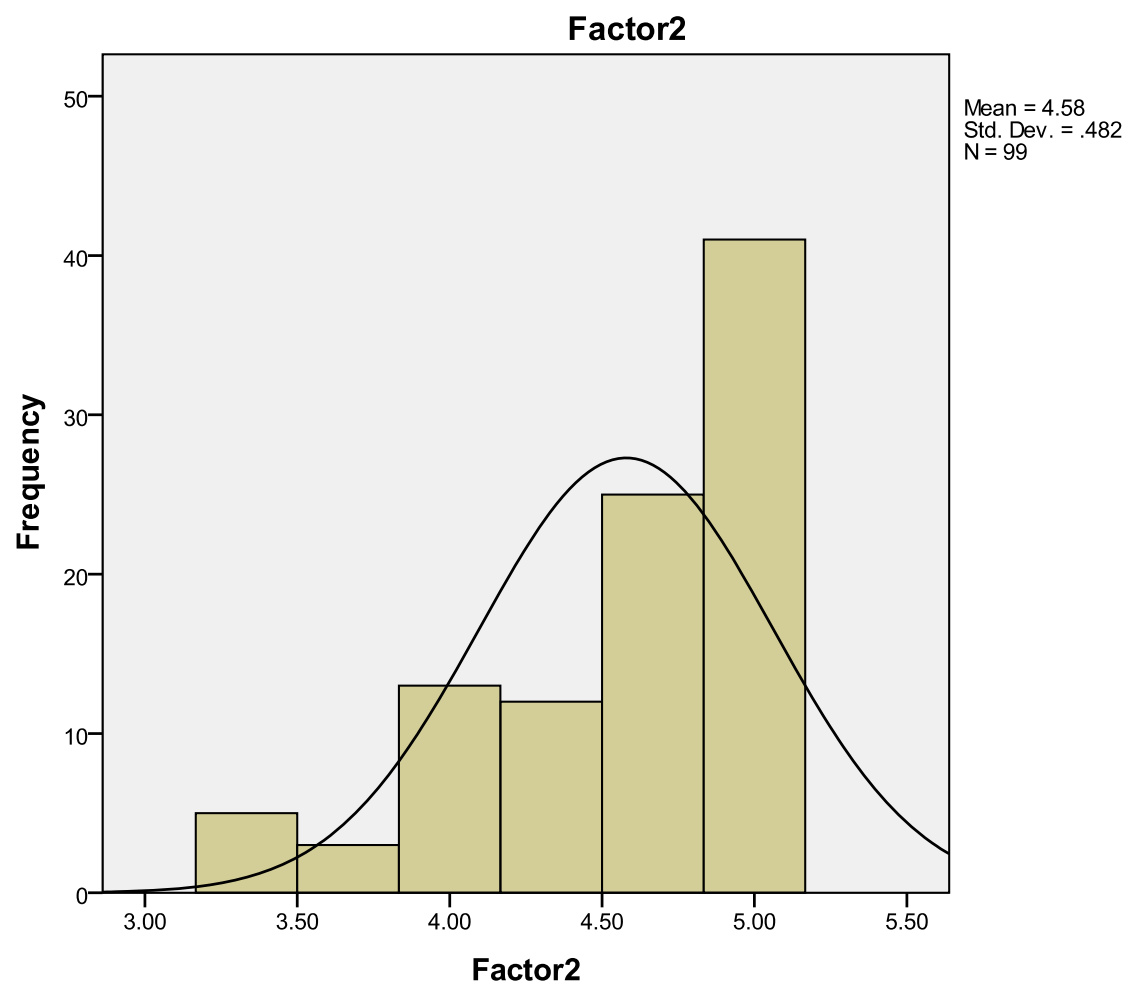


Figure 7. Senior managers' frequency histogram of Factor 3 (Concern)

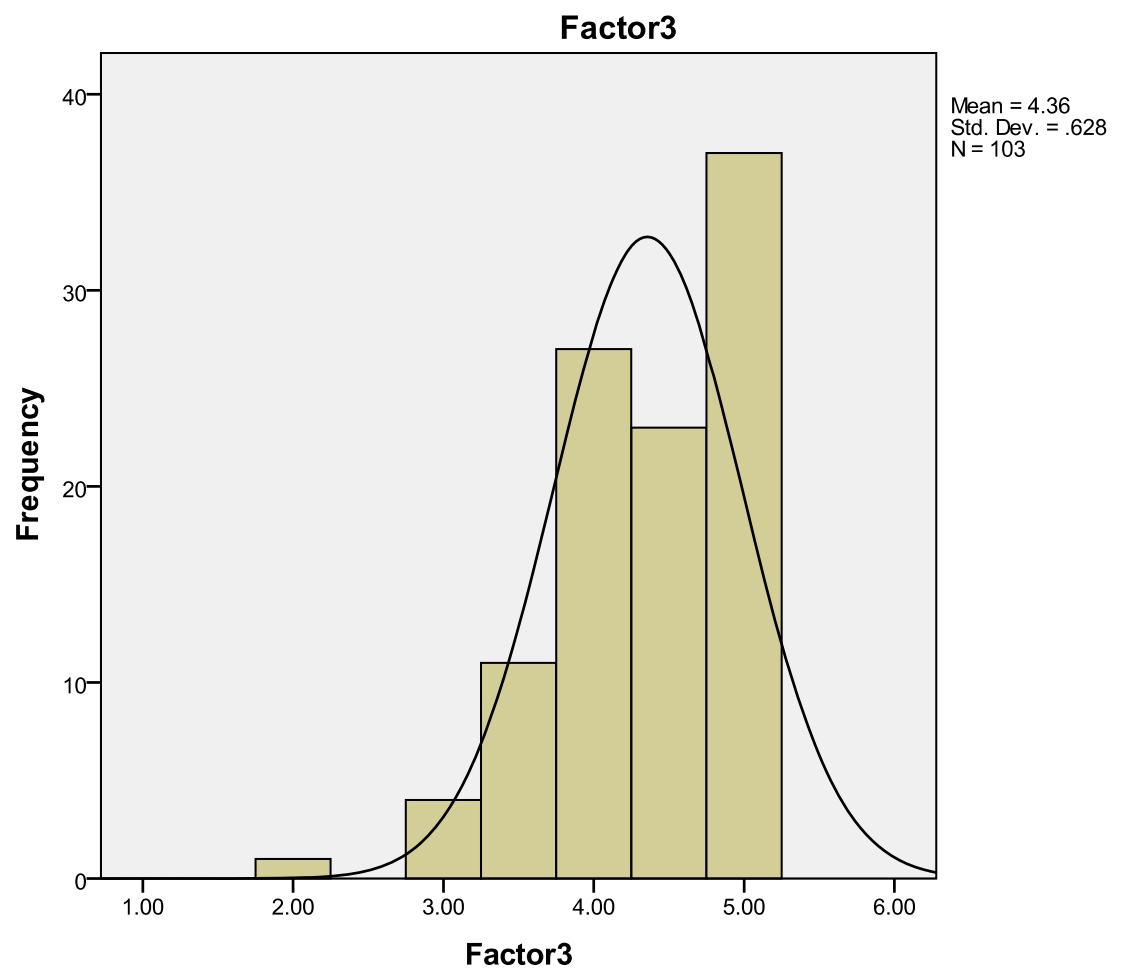

Figure 8. School staff's frequency histogram of attitudes towards cyberbullies

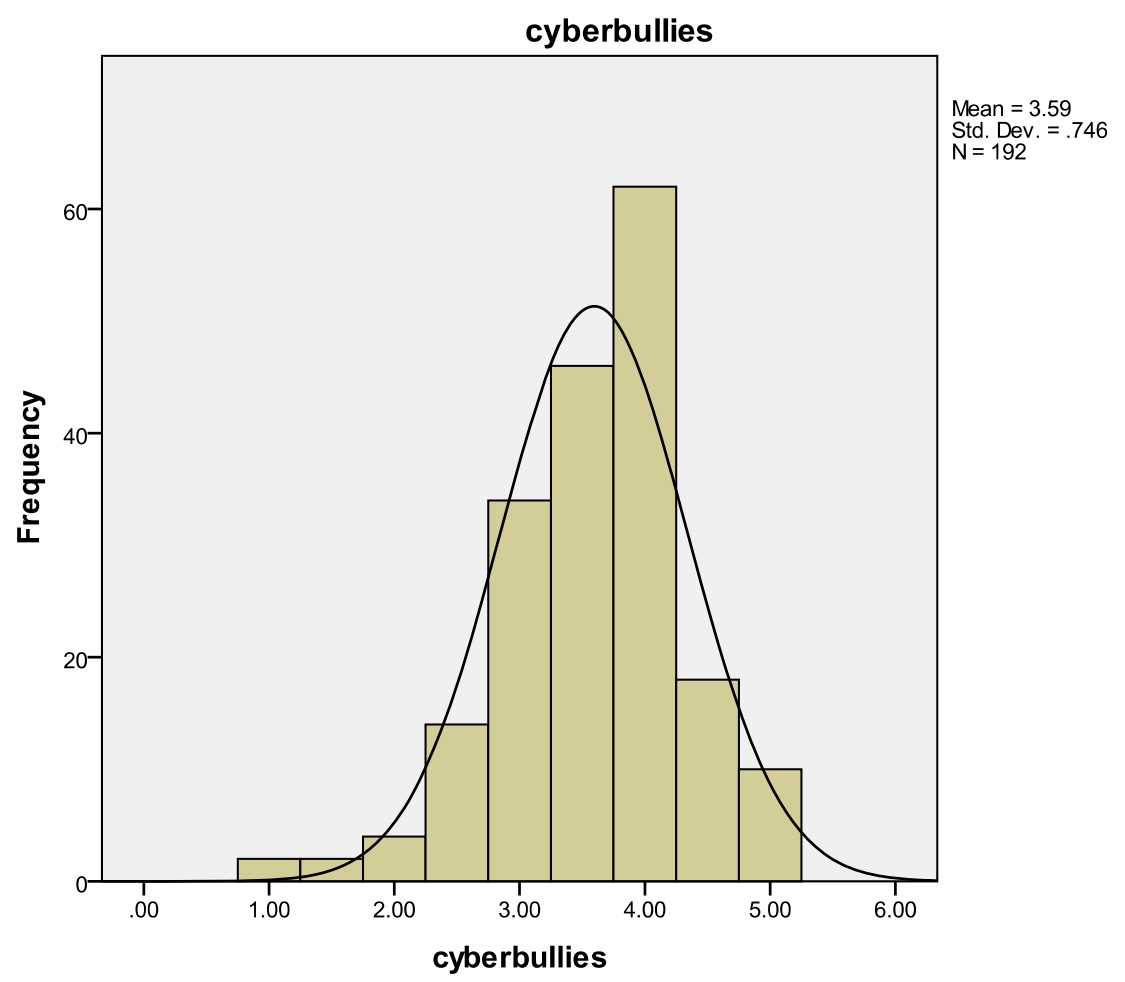


